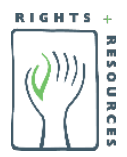

RIGHTS AND RESOURCES INITIATIVE | OCTOBER 2017

\title{
The Green Climate Fund: Accomplishing a Paradigm Shift?
}

Analysis of the GCF Approach to Safeguards, Indigenous Rights, and Participatory Processes

Anne Perrault and Stephen Leonard 


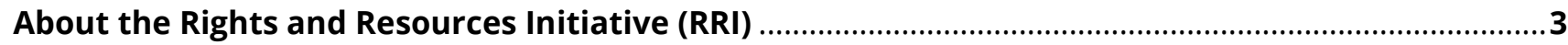

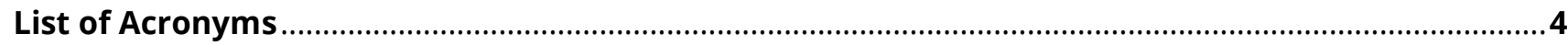

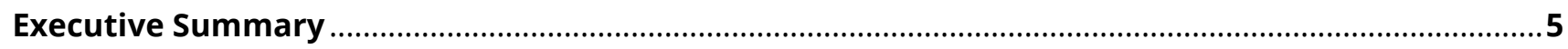

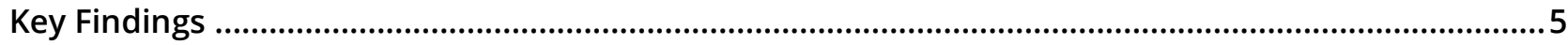

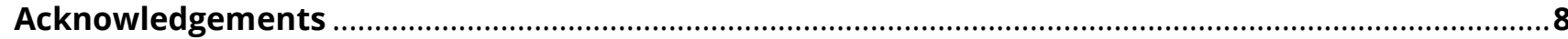

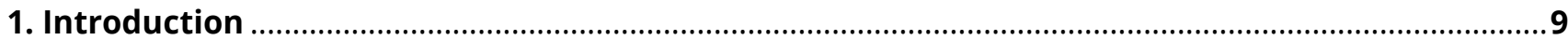

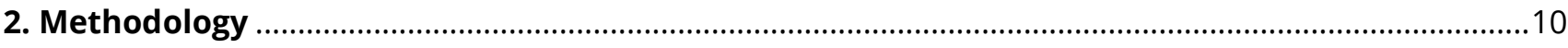

3. Findings

3.1: Uneven Application and Enforcement of Interim Environmental and Social Standards..............12

3.2: Downgrading of Risks and Safeguards Requirements ................................................................... 14

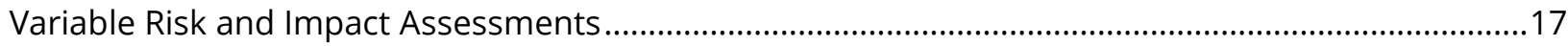

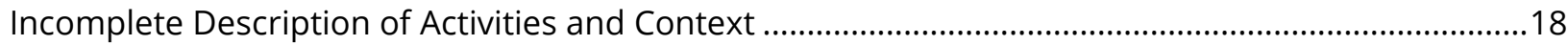

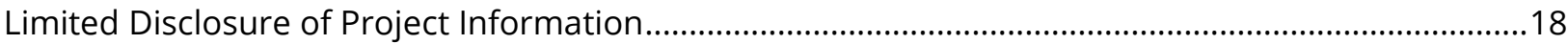

3.3: Limited Guidance for Financial Intermediaries of Accredited Entities .........................................19

3.4: Inadequate Protection of Indigenous Peoples', Local Communities', and Rural Women's

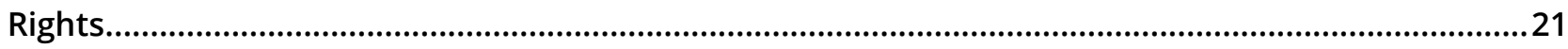

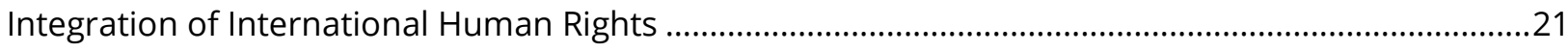

Balancing National and International Laws Concerning Land and Resource Rights ...........................22

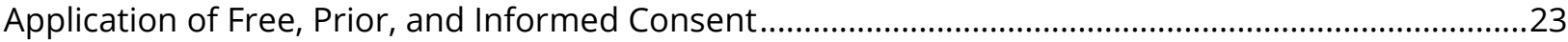

Impacts on Indigenous Peoples', Local Communities', and Women's Rights and Livelihoods..............25

3.5: Variable Stakeholder Engagement, Benefit Sharing, and Grievance Redress Mechanisms.........27

Limited Community Participation in Project Design, Appraisal, and Implementation ..........................28

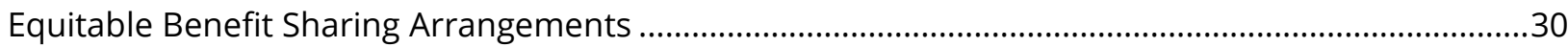

Incomplete Grievance Redress and Dispute Resolution Mechanisms .................................................30

Variable Safeguards, Stakeholder Engagement, and Benefit Monitoring Approaches.........................32

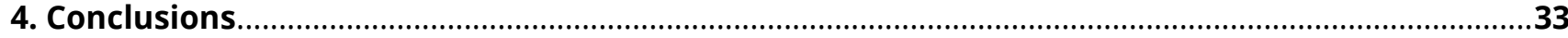

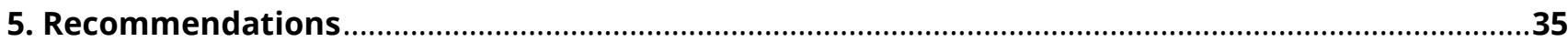




\section{About the Rights and Resources Initiative (RRI)}

RRI is a global coalition consisting of 15 Partners, 7 Affiliated Networks, 14 International Fellows, and more than 150 collaborating international, regional, and community organizations dedicated to advancing the forestland and resource rights of Indigenous Peoples and local communities. RRI leverages the capacity and expertise of coalition members to promote secure local land and resource rights and catalyze progressive policy and market reforms.

RRI is coordinated by the Rights and Resources Group, a non-profit organization based in Washington, DC. For more information, please visit www.rightsandresources.org.

\section{Partners}
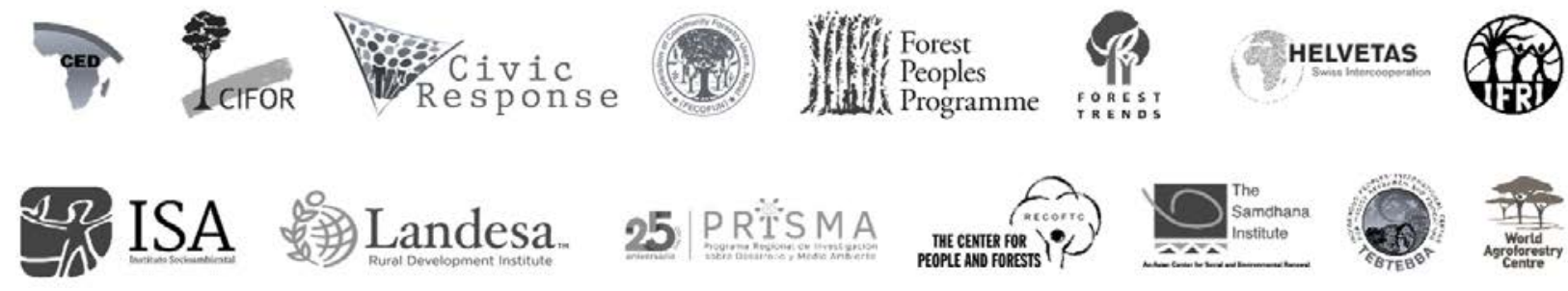

\section{Affiliated Networks}
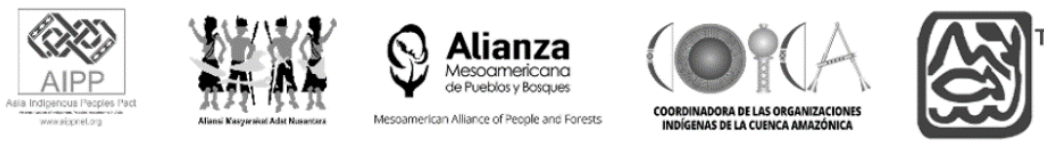

The Internationa Association for the Study of the Commons
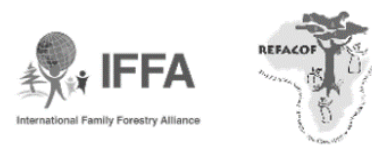

\section{Sponsors}
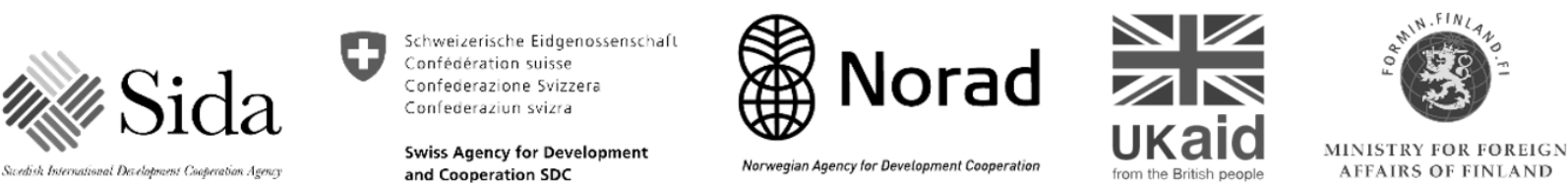

\section{8\% FORDFOUNDATION}

The views presented here are not necessarily shared by the agencies that have generously supported this work nor by all the Partners and Affiliated Networks of the RRI Coalition. This work is licensed under a Creative Commons Attribution License CC BY 4.0. 


\section{List of Acronyms}

\begin{tabular}{|c|c|}
\hline $\mathrm{AE}$ & Accredited Entity \\
\hline AMA & Accreditation Master Agreement \\
\hline CDB & Caribbean Development Bank \\
\hline $\mathrm{Cl}$ & Conservation International \\
\hline CSO & Civil Society Organization \\
\hline DBSA & Development Bank of South Africa \\
\hline E\&S & Environmental \& Social \\
\hline EbA & Ecosystems Based Adaptation \\
\hline EIB & European Investment Bank \\
\hline ESERN & Environmental, Social and Economic Review Note (UNEP tool) \\
\hline ESMP & environmental and social management plan \\
\hline ESMS & environmental and social management system \\
\hline ESS & environmental and social standards \\
\hline $\mathrm{FI}$ & financial intermediary \\
\hline FPIC & free, prior, and informed consent \\
\hline GCF & Green Climate Fund \\
\hline IDB & Inter-American Development Bank \\
\hline IFC & International Finance Corporation \\
\hline ILO & International Labour Organisation \\
\hline IRM & Independent Redress Mechanism \\
\hline ITAP & Independent Technical Assessment Panel \\
\hline MSME & micro, small and medium enterprise \\
\hline NCU & National Compliance Unit \\
\hline NDA & National Designated Authority \\
\hline PROFONANPE & Peruvian Trust Fund for National Parks and Protected Areas \\
\hline PS & Performance Standard \\
\hline REDD+ & $\begin{array}{l}\text { Reducing Emissions from Deforestation and Forest Degradation, as well as } \\
\text { conservation, sustainable management of forests, and enhancement of forest carbon } \\
\text { stocks }\end{array}$ \\
\hline SESP & Social and Environmental Screening Procedure \\
\hline UNEP & United Nations Environment Programme \\
\hline UNDRIP & United Nations Declaration on the Rights of Indigenous Peoples \\
\hline UNDP & United Nations Development Programme \\
\hline VGGT & $\begin{array}{l}\text { Voluntary Guidelines on the Responsible Governance of Tenure of Land, Fisheries and } \\
\text { Forests in the Context of National Food Security }\end{array}$ \\
\hline
\end{tabular}




\section{Executive Summary}

The Green Climate Fund (GCF), established in 2010 at the $16^{\text {th }}$ Conference of Parties (COP16) under the United Nations Framework Convention on Climate Change (UNFCCC), is now the world's largest climate financing institution. It has a current investment portfolio of 43 approved projects totaling around US $\$ 2$ billion, and has 48 Accredited Entities (AEs) to support implementation, including UN agencies, banks, NGOs, and private companies.

Through its investments, the GCF aims to achieve a paradigm shift in developing countries, toward low-emissions development and climate resilience. GCF investments must indicate whether and how they could impact Indigenous Peoples, local communities, and women who are most at risk from the adverse effects of climate change (e.g. via environmental and social management plans). These goals, however, are currently being challenged by inadequacies in the Fund's policies and frameworks. GCF safeguards fail to recognize the critical contributions of rural peoples to the maintenance of ecosystem services that are essential to international climate and development objectives, and to offer adequate protection for their land and resource rights.

Drawing on international standards and GCF policy documents, this report traces the adequacy and implementation effectiveness of the Fund's current institutional frameworks across a representative sample of approved projects. Noting critical gaps in nearly every aspect of the Fund's operational modalities and project approval processes, the report calls on the GCF to take progressive steps to make Indigenous Peoples' and local communities' rights a key part of its climate actions going forward.

\section{Key Findings}

\section{Uneven application and enforcement of interim environmental and social standards}

(ESS). Study results reveal a clear departure from the GCF's commitment to apply its interim environmental and social standards to all its investments. The GCF master agreement with Accredited Entities (AEs) allows the use of the standards of the relevant $A E(s)$, but without an open, thorough validation process to ensure these standards are at least equivalent to those of the GCF. Project documents show that these standards are often less robust than the GCF's own interim ESS, and applied standards are inadequate to address the land and resource rights of Indigenous Peoples and local communities. Moreover, GCF policies do not clearly require application of all standards to activities of financial intermediaries (FIs) to AEs.

Miscategorization of risks. GCF policies do not ensure that risks are accurately identified and categorized. Project documents reveal miscategorization and downgrading of higher-risk 
investments, which in turn minimizes the level of required consultation, transparency, monitoring, and mitigation. When requirements are reduced for projects impacting the livelihoods and tenure rights of Indigenous Peoples and local communities, the consequences not only jeopardize the likelihood of success, but also weaken the credibility of the GCF and its counterparts. Limited disclosure of relevant information likewise hinders third party assessment of identified project risks.

\section{Limited recognition and protection of Indigenous Peoples', local communities', and} women's rights. GCF standards note that it may be appropriate for a client to complement environmental and social risks and impacts assessments with specific human rights due diligence in limited high risk circumstances only. Similarly, measures to ensure respect for the customary tenure and resource rights of Indigenous Peoples and local communities, as recognized under international law, are absent from the current GCF policy framework. While the Fund supports those rights "recognized or recognizable" under national law, consistency with international law and standards, including UNDRIP, is framed merely as an expectation, not a requirement. Failure to uphold international law and norms, including those in the International Labour Convention (ILO 169), the Voluntary Guidelines on the Responsible Governance of Tenure (VGGT), the UN Guiding Principles on Business and Human Rights, the UN Declaration on the Rights of Indigenous Peoples (UNDRIP), and other instruments invariably undermines the system-level changes that are now urgently needed to bring about impactful climate actions and solutions.

Weak enforcement of free, prior, and informed consent (FPIC). Lax implementation requirements and project-level discretionary authority to define an investment's area of influence and possible impacts on Indigenous Peoples and local communities have resulted in the limited application of free, prior, and informed consent (FPIC). Failure to recognize and enforce FPIC as a process of continuous engagement anchored in clear and common principles, including those set out in ILO 169 and UNDRIP, ultimately weakens the Fund's ability to rigorously enforce FPIC across its investments.

Variable stakeholder engagement, benefit sharing, grievance/redress mechanisms, and project monitoring. Evidence of stakeholder engagement was noted across reviewed GCF projects, but the timeliness and comprehensiveness of consultations is inconsistent. Similarly, benefit-sharing processes and concern for gender equality were satisfactorily addressed in the majority of projects, though involvement of affected communities and primary beneficiaries in the design of proposed interventions was generally unclear. Over half of the projects analyzed referenced project-level grievance mechanisms, but only three provided clear definitions of process. Monitoring frameworks likewise varied significantly, with only minor attention to 
environmental and social impacts compared with the distribution of project benefits.

Now that the importance of Indigenous Peoples' and rural communities' engagement stands to be affirmed in the Fund's new Indigenous Peoples' policy ${ }^{1}$ - with revised policies on safeguards, REDD $+^{2}$ financing, results-based payments, and benefit-sharing mechanisms expected soonthe GCF is clearly poised to better protect the rights of rural peoples across all its investments. Yet, as our analysis makes clear, greater attention will need to be placed on the implementation and enforcement of the standards and safeguards that underpin its mission, and this will be incumbent on the Fund itself as well as Accredited Entities and National Designated Authorities (NDAs). To this end, it will be fundamental to the Fund's success to protect the land and resource rights of those who have for generations stewarded the lands, forests, and biodiversity that the world depends on to meet its development and climate commitments.

\section{Recommendations}

To strengthen results, the GCF should:

- Adopt rights-based approaches for all its policies and investments, including the protection of rural land and resource rights;

- Adopt a stand-alone Indigenous Peoples' policy as soon as possible;

- Apply robust environmental and social standards across chain of custody;

- Enforce FPIC per international standards and legal precedents;

- Strengthen due diligence on risk identification and mitigation;

- Reinforce stakeholder engagement processes;

- Increase the transparency of project documentation, reviews, and approvals; and

- Independently monitor compliance. 


\section{Acknowledgements}

This report is a collaboration between independent consultants, and staff of the Rights and Resources Group, the secretariat of the Rights and Resources Initiative. The report was written and produced by Anne Perrault, Stephen Leonard and Alain Frechette, with technical support from Natalie Campbell, and was revised and edited for publication by Alain Frechette. Important contributions were made from expert reviewers, including Amy Duchelle (CIFOR), Kate Dooley (University of Melbourne), Andrea Rodriguez (AIDA), Liane Schalatek (Heinrich Boll Foundation), Francesco Martone (Tebtebba), and Helen Magata (Tebtebba). Valuable comments and feedback on the report findings and conclusions were also provided by reviewers from Conservation International, the UN Development Programme, and the Green Climate Fund Secretariat. 


\section{Introduction}

The Green Climate Fund (GCF) was established in 2010, at the $16^{\text {th }}$ Conference of Parties (COP16) under the United Nations Framework Convention on Climate Change (UNFCCC), to promote a paradigm shift in developing countries toward low-emission and climate-resilient development. Today, the GCF is the world's largest climate financing institution. It has a current investment portfolio of 43 approved projects totaling around US $\$ 2$ billion, and has 48 Accredited Entities (AEs) to support implementation, including UN agencies, banks, NGOs, and private companies.

Designed to support the needs of developing country parties to the UNFCCC, with a special focus on climate-vulnerable populations in Least Developed Countries (LDCs), Small Island Developing States (SIDS) and African States, GCF investments must indicate whether and how they could impact Indigenous Peoples, local communities, and women who are most at risk from the adverse effects of climate change. As referenced in the preamble of the Paris Agreement, all Parties should consider climate actions that "respect, promote and consider obligations on human rights... the rights of indigenous peoples, local communities, migrants, children, persons with disabilities and people in vulnerable situations and the right to development, as well as gender equality, empowerment of women and intergenerational equity." ${ }^{3}$ Recognizing that such actions should be pursued on the basis of equity, and in the context of sustainable development and efforts to eradicate poverty (per Article 4.1), each of these considerations should extend to the GCF, and the extent to which its investments are likely to support such goals.

This report presents the first detailed assessment of the Fund's responsiveness to, and inclusion of, Indigenous Peoples' and local communities' rights. Drawing on international standards, commitments, and legal precedents, the report considers: (i) the extent to which current GCF institutional frameworks and safeguards are adequate to support stakeholder engagement, participation, and consultations in the design and delivery of GCF project interventions; (ii) whether the rights and livelihoods of rural communities are clearly considered and protected in relevant and approved GCF projects; and (iii) whether institutional frameworks and safeguards of AEs comply with GCF standards and/or international best practice. In doing so, the report tackles important issues related to safeguard implementation, the role of financial intermediaries, the application of free, prior, and informed consent (FPIC), benefitsharing arrangements, grievance redress mechanisms, and project-related risk assessments as expressed in publicly available documentation. 
The GCF has undertaken a number of steps to make indigenous and community rights part of its climate actions and decision-making processes. The obligation to respect the rights of Indigenous Peoples and fully and effectively engage them in the design and delivery of projects it finances feature prominently in the Fund's Governing Instrument, ${ }^{4}$ interim Environment and Social Standard (ESS), ${ }^{5}$ draft Environment and Social Management Standards, ${ }^{6}$ and Independent Redress Mechanism. ${ }^{7}$ Moreover, policies on safeguards, REDD+ financing, results-based payments, and benefit-sharing mechanisms are expected to be revised soon, and an Indigenous Peoples' policy should be submitted for Board approval before the end of $2017 .{ }^{8}$

Nevertheless, study findings reveal critical gaps in the way indigenous and local community rights are addressed in the current GCF policies and safeguards, and how these are then interpreted and implemented in the context of project review and approval processes. The report makes it clear that in order to achieve an inclusive and sustainable paradigm shift toward low-emissions development and climate resilience, GCF investments will also need to protect the rights of those who have for generations stewarded the lands, forests, and biodiversity that the world now depends on to realize its climate commitments.

\section{Methodology}

The results of this study are drawn from a comparative desk review of the GCF project portfolio and analysis of applied performance standards, environmental and social safeguards, and policy frameworks. Selected projects were screened on the bases of their:

- Relevance to land, water, forest, or other resource sectors and potential impacts on collective rights-whether legal or customary (i.e., used to assess the likelihood of impact); and

- Regional representativeness for Africa, Asia Pacific, and Latin America and the Caribbean.

Of the 37 projects considered when this project began, 18 received high-impact probability scores; nine were rated as moderate; and 10 were judged to have low or no potential impacts on Indigenous Peoples, local communities, or rural women. Of those rated high probability of impact, a subsample of 11 projects were selected for analysis, including two from Asia Pacific, two from Latin America, four from Africa, and three from small island states (Maldives, Tuvalu, and the Cook Islands). 
To assess the rigor of selected project with respect to indigenous, community, and women's rights, an analytical framework was developed, drawing on established international standards and GCF-endorsed guidelines. In all, 24 indicators divided into four distinct categories were produced, covering the Fund's: (i) policy guidelines; (ii) safeguards framework; (iii) project submissions; and (iv) monitoring and oversight function. Consistency in the application of identified standards and guidelines was assessed using a three-tier rating system, with supporting evidence drawn from GCF policy documents, project/programme submissions, Board decisions, and other related publications.

Further to these considerations, the review considered the GCF's approach to the implementation of adopted policy guidelines and safeguards, including compliance with IFC standards and other broader policy concerns.

This review was constrained by the unavailability of key documents, including screening and risk assessment results, environmental and social management plans, gender plans, stakeholder engagement plans, accreditation reviews and some accreditation master agreements, Secretariat assessments of proposals and AE standards, and most Funded Activity Agreements (FAA). While an information disclosure request form was submitted to the GCF and a number of documents were subsequently made available, the added information did not change the main conclusions of this report.

To validate emerging findings and areas of recommendation, consultations with expert reviewers were held between March and May 2017, resulting in input from Accredited Entities, civil society organizations (CSO), and Indigenous Peoples' representatives. Further, an informal consultation was held on the sidelines of the GCF's $16^{\text {th }}$ meeting of the Board at the GCF Headquarters in Songdo, South Korea in April 2017, and preliminary findings and recommendations were presented and discussed at a side event of the Bonn Climate Change Conference during May 2017 (SB 44).

This study looks at how GCF's interim standards and policies are being applied, including those related to risk categorization, AE funding through financial intermediaries, and transparency. The document explores the way in which the interim standards address international and national law and recognize rights and the application of free, prior, and informed consent. We review projects and polices relative to each of these matters, as well as stakeholder participation, benefit sharing, grievance redress mechanisms, and monitoring frameworks. 


\section{Findings}

\section{1: Uneven Application and Enforcement of Interim Environmental and Social Standards}

The GCF adopted the International Finance Corporation (IFC) Performance Standards (PS) as its interim environmental and social standards (ESS) in 2014 (see Table 1 below), to be applied to all approved projects and programs implemented through Accredited Entities (AEs) to the GCF. ${ }^{9}$ Reviewed project documents, however, reveal inconsistent application of the Fund's interim ESS.

Table 1. IFC Performance Standards

\section{Overarching (ESMS)}

PS1: Assessment and Management of

Environmental and Social Risks and Impacts

- Policy (or equivalent documents)

- Process for identifying risks \& impacts

- Management Programme

- Organisational capacity \& competency

- Process for monitoring and evaluation

- External communications

\section{Subject Specific}

PS2: Labour and Working Conditions

PS3: Resource Efficiency, Pollution

Prevention

PS4: Community Health, Safety and

Security

PS5: Land Acquisition and Involuntary

Resettlement

PS6: Biodiversity Conservation and

Sustainable Management of Living

Natural Resources

PS7: Indigenous Peoples

PS8: Cultural Heritage

Specifically, AEs are applying their own standards, even if less rigorous than those of the IFC. The GCF's accreditation process, including the Accreditation Master Agreements (AMAs) and the fit-for-purpose accreditation approach, enables this.

The AMA template explicitly allows an AE to use its own standards, stipulating that this "should enable it to comply with the Fund's Standards."10 The GCF thus assumes that its fit-for-purpose accreditation approach is robust enough to ensure that $A E$ standards are at least equivalent to those of the GCF. ${ }^{11}$ Unfortunately, this is not the case for several reasons. 
First, evidence suggest that the accreditation review of AE standards, against the GCF's ESS, is not an open and deliberative process: the GCF relies on a closed review and accreditation panel, with limited obligation to publicly disclose all relevant information. ${ }^{12}$ Second, the checklist used for the review does not clearly require that AE standards include all relevant Performance Standards requirements. Although the introduction to the checklist indicates that the "end goal ... is to have a reasonable assurance that the entities have systems, process and staff in place ... to make consistent decisions on E\&S issues in line with the Green Climate Fund's ESS," it notes (Item 6.1) that the policy should be consistent only with the "principles of the Performance Standards." And third, the accreditation review checklist does not include questions about the ESS. The AMA template notes that an AE must apply the Fund's Standards only if: (1) its standards are revised in a way that leaves it non-compliant with those of the Fund; or (2) gaps are identified, revealing the application of less stringent standards.

The implied invitation in the AMA template to apply alternative standards was used by eight of the 11 reviewed projects. Documentation available for these projects does not provide information or assurances detailing how alternative standards will ensure compliance with the GCF's interim ESS. To the contrary, our review of these alternatives indicates that most accepted AE standards fall short of the GCF's interim ESS.

A case in point is the "Large-scale Ecosystem-based Adaptation" project in Gambia (The Gambian EbA Project). The proposal does not indicate how the safeguards framework of the United Nations Environment Programme (UNEP)-the designated AE-measures up to GCF's interim ESS. Relevant social and environmental safeguards, including the environmental and social assessment standard, Indigenous Peoples' standard, cultural heritage standard, and displacement standard, are not explicitly mentioned or systematically addressed in the document. Proposal references to environmental and social safeguard measures to manage risks are limited to national policies and laws, ${ }^{13}$ and a referenced Annex with results of the Environmental, Social, and Economic Review Note (ESERN) is not publicly provided. ${ }^{14}$

Similarly, the approved project for Catalyzing Private Investment in Sustainable Energy in Argentina (Sustainable Energy Project) indicates that Inter-American Development Bank (IDB) safeguards are to be applied. While project documents state that IDB safeguards will be "evaluated" and "reviewed" against "best practice standards such as the IFC Performance Standards," compliance with these is not clearly referenced. Accreditation process documents do not indicate how IDB's safeguards substantively compare with those of the GCF, nor how potential gaps would be addressed thereafter. Information regarding conditions or recommendations for IDB accreditation, e.g., the AMA Agreement between the IDB and GCF, is not accessible to the public. 
One AE-the Caribbean Development Bank (CDB)-for which a GCF project has not yet been approved, but which serves as a financial intermediary (FI) in another project (the IDB's Caribbean Sustainable Energy Facility Project - Caribbean SEF Project), relies on more broadly defined standards than those of the GCF. While the CDB's procedure does list the same eight Performance Standards as the IFC (see Table 1 above), it does not include the same substantive requirements. A review of the $C D B^{\prime} s$ standards reveals, for example, no requirement for free, prior, and informed consent (FPIC), and protections for Indigenous Peoples are generally weaker than those of the IFC. The CDB's use of a "consultation" standard, in lieu of FPIC for Category A high risk projects (see Table 2 below) for which it is accredited, means the risk of significant impacts for Indigenous Peoples may go undiagnosed and/or unaddressed. Responding to the accreditation panel's assessment of the CDB, the GCF Board nevertheless concludes that " $\mathrm{t}$ ] he applicant partially meets the requirements of the interim environmental and social safeguards of the GCF in relation to high E\&S risk (Category A/I-1)." ${ }^{15}$ In the end, the Board presented neither recommendations nor conditions to strengthen the CDB's standards.

Given evidence that environmental and social standards for at least some AEs are not comparable to those of the GCF, that the safeguards review process cannot be monitored by third parties (and is therefore neither open nor transparent), ${ }^{16}$ and that public disclosure of information on emerging gaps is altogether limited, the assumption that an AE's compliance with its own standards "should enable it to comply with the Fund's standards" leaves much to be desired. Instead of encouraging a race to the top, the GCF is providing a convenient loophole for AEs. This assumption may promote a reactionary approach to adverse impacts to communities and the environment, creating unnecessary problems and suggesting a willingness to address them only after "gaps" have been identified.

\section{2: Downgrading of Risks and Safeguards Requirements}

The categorization of risks involves the identification and grading (see Table 2 below) of the possible repercussions of a given set of programmatic interventions in a given social, political, economic, and biophysical environment. In turn, a priori categorization affects how safeguards are interpreted and applied, including: how thoroughly impacts are assessed; the amount of information available to communities ${ }^{17}$; when and how stakeholders are informed and engaged ${ }^{18}$; the depth and scope of the proposed environmental and social management system; whether an environmental and social policy is required; and ultimately, the risk mitigation strategy that will be employed. ${ }^{19}$ As such, the value of a given set of safeguards ultimately depends on whether risks to communities and/or the environment are accurately identified and evaluated prior to mitigation attempts. Mischaracterization or downgrading of such risks, based on the assumption that proposed mitigation strategies will yield their desired 
effects, undermines both the anticipated and unanticipated consequences of the proposed intervention and the importance of stakeholder buy-in and support for the realization of stated results-including the rights of affected populations. ${ }^{20}$

Table 2. Risk Categories and Definitions (Green Climate Fund Handbook, WRI 2015)

Category

High Risk Activities:

Category A or 11

Medium Risk Activities:

Category B or 12

Low Risk Activities:

Category $\mathrm{C}$ or $\mathrm{B}$

\section{Definition}

"Activities with potential significant adverse environmental or social risks and/or impacts that are diverse, irreversible, or unprecedented."

"Activities with potential limited adverse environmental or social risks and/or impacts that are few in number, generally site-specific, largely reversible, and readily addressed through mitigation measures."

"Activities with minimal or no adverse environmental or social risks and/or impacts." Category C projects do not require environmental and social action plans or reporting.

Our review of GCF guidance on risk points to four distinct limitations in the way risks are identified and categorized. These limitations relate to (i) how risk is defined; (ii) who defines risk; (iii) the processes used to define risk (e.g., opportunities for open and deliberative justification); and (iv) the degree of oversight or due diligence from the Fund.

Reviewed projects tend to define "risk" as exposure to a specific concern after mitigation measures have been applied, with the built-in assumption that these will be effective. While the GCF's Environment and Social Management System and IFC Policy ${ }^{21}$ acknowledges that risks should be assessed prior to mitigation efforts, project documents do not reflect such an understanding.

An example of miscategorization, and its potential impact on Indigenous Peoples, is the Building Resilience of Wetlands Project (Peru Wetland Project), led by the Peruvian Trust Fund for National Parks and Protected Areas (PROFONANPE). While PROFONANPE is accredited for Category $C$ low risk projects, the proposed initiative stands to affect the land rights of some 120 indigenous communities, including more than 20,000 people. ${ }^{22}$ Noting that the targeted area has had a "long history of mistrust in the relationship between ancestral communities, 
settlers/migrants and government officials," ${ }^{23}$ project risks were nevertheless categorized as being low by the proponent, based on the assumption that these would be controlled with mitigation measures. Consequently, potential impacts on community land rights are altogether obscured in the proposal, including implications for the Land Acquisition and Involuntary Resettlement Standard (PS5). ${ }^{24}$ Other risks insufficiently detailed include the potential for conflicts between and within communities, and between the latter and governments or other entities. Such risks, which are common in projects that affect land and resource rights, should be evaluated before they can be dismissed. This project is explored further below in the context of FPIC.

The Gambian EbA Project proposal illustrates similar shortcomings in terms of risk classification and potential impacts on Indigenous Peoples and local communities. The project is said to be located on indigenous territories, with direct and indirect benefits for more than 11,000 and 46,000 individuals respectively, in at least 125 communities. Although the proposal flags a number of significant concerns, such as the "risk that the project will negatively affect land tenure arrangements, including communal and/or customary/traditional land tenure," not to mention the strong probability that it will "negatively affect livelihoods of indigenous peoples by influencing the rights, lands and territories claimed by these people," ${ }^{25}$ overall project risk was rated low (i.e., Category C). This appears to be based on the assumption that mitigation measures will prevent or mitigate any and all potential risks, thus avoiding the need to address critical safeguard requirements, including those related to the land and resource rights of Indigenous Peoples, and the need to publicly disclose any environmental and social report. ${ }^{26}$

The Vulnerable Communities in Maldives to Manage Climate Change-Induced Water Shortages Project (Maldives Water Project) plans to recharge groundwater aquifers with untreated greywater (among other measures). The submission notes that "recharging of untreated greywater can give rise to infectious diseases and moreover make the groundwater unusable." While such an occurrence would have detrimental long-term impacts in nearly any setting (i.e., a Category A concern), the project is rated Category $B$, which, as noted in project documentation, is due to reliance on mitigation measures. It states that recommended measures described in Section F.3 of the proposal will greatly reduce "the risks of any short to long term significant impacts." Further challenging this categorization is the lack of a description in Section F.3 of the recommended measures.

Obviously, low risk categorization allows projects to avoid the more extensive requirements of higher risk categories and levels of accreditation, including those related to stakeholder engagement, consultations, baseline information, application of an environmental and social policy, and plans to address risks. ${ }^{27}$ Evidence drawn from this analysis suggests that risk 
identification and assessments by project proponents, combined with weak review processes, effectively allow AEs to shoehorn their projects into the lower risk categories for which they were accredited. This practice is of particular concern for projects involving Indigenous Peoples, as miscategorization substantially reduces the burden of due diligence, which, as noted by IFC, "is of particular significance when a proposed activity triggers the PS 7 requirement for FPIC of indigenous peoples." 28

\section{Variable Risk and Impact Assessments}

The IFC provides only general guidance for assessing potential project risks. It indicates for instance that the "type, scale, and location of the project [should] guide the scope and level of effort," and that "the risks and impacts identification process [should] be consistent with good international industry practice," and draw "on recent environmental and social baseline data at an appropriate level of detail." ${ }^{29}$

The Peru Wetlands Project reflects this shortcoming. Although the proposal flags a number of potential risks, including the fact that "39 percent of the province lacks clear land tenure status," that "43 percent of the land that could have legal title has not been legalized," that Indigenous Peoples have faced a "long fight...to gain legal tenure of their territories," and that there are "[m]any barriers ... to land titling in Peru," no attempt is made to proactively address these concerns within the scope of the project. ${ }^{30}$ The potential impacts of project activities in a complex and challenging context are briefly acknowledged, ${ }^{31}$ yet pre-emptive measures to minimize risks are insufficient. The Gambia EbA Project similarly fails to identify and address key land and resource rights-related risks.

GCF's Guidelines for Operationalization of the Fit-for-purpose Accreditation Approach indicate that risks associated with projects involving high numbers of indigenous communities and land tenure concerns, such as the Peru Wetlands project and The Gambian EbA Project, are usually high. Although the Guidelines specifically mention projects carried out in "areas of importance for indigenous peoples or other vulnerable groups" as examples illustrative of Category A high risk projects, ${ }^{32}$ both projects were rated as Category C low risk activities. The Inspection Panel to the World Bank corroborates the risky nature of such projects. In its review of 30 years of complaints to the Panel, it states "projects involving indigenous peoples are highly complex, technical, and sensitive." ${ }^{\prime 33}$ Accurately characterizing the "high risk" nature of these projects ensures that mitigation measures respond to the risks, that decision-making processes are clear and transparent, and that Indigenous Peoples are heard and respected.

Appraisal of project risks and impacts were found to be clearly justified in at least five of the projects reviewed. Risks were appropriately graded in the Caribbean SEF Project (Category A), 
though still undefined at the subproject level. Similarly, the World Bank's Climate Adaptation and Mitigation Program for the Aral Sea Basin (CAMP4ASB Project), the South African Project on Micro, Small, and Medium Enterprises (South African MSME Project), Argentina's Sustainable Energy Project, and the Pacific Islands Renewable Energy Investment Program (Pacific RE-Invest Project) appear to have been correctly appraised (all Category B), given the information provided in submissions.

\section{Incomplete Description of Activities and Context}

Activities that could impact Indigenous Peoples and local communities were underreported in at least four of the 11 reviewed projects. One compelling example of this is the Peru Wetlands Project. The project's executive summary emphasizes activities focused on community development without addressing the relationship between the community-focused activities and the project's support for a new protected area and a zoning plan. The proposal purports benefits for communities, but there is no clear commitment to ensuring that community decisions related to their territories will be respected. ${ }^{34}$ To the contrary, the project document shows that such decisions may in fact be constrained. ${ }^{35}$

Further, two of the projects analyzed do not provide a complete description of the contextincluding an accurate description of the existence of Indigenous Peoples and local communities and their land and resources in the project area. The Gambian EbA Project seeks to support rural communities, but the existence of Indigenous Peoples is not referenced until page 47, and their rights are neither specified nor assessed. Similarly, the proposal for Climate Resilient Agriculture in Namibia (CRAVE Project) focuses its attention on small-scale farmers. Yet, it only briefly references the fact that at least some of the communities involved are Indigenous Peoples, and related impacts are not assessed.

\section{Limited Disclosure of Project Information}

Lack of readily accessible project documentation on risks and safeguards makes it difficult to independently monitor and verify compliance with GCF standards and protocols in real time. Though the GCF Secretariat is responsive to information requests, the non-disclosure entitlement of environmental and social reports for Category $C$ projects makes it challenging to undertake independent assessments of purported risks and applied safeguards measures. Examples of documents that were not publicly disclosed at the time of this analysis are presented in the box text on the next page. 


\section{Examples of Missing Project Documents}

- The Gambian EbA Project Annexes concerning safeguards, results of the ESERN, gender analysis, and the proposed approach for engagement and coordination of the project's multiple stakeholders during the implementation stage. The Annex section of the document states, "Environmental and social report disclosure not required for Category $\mathrm{C}$ and Intermediation 3 projects and programmes;"

- $\quad$ PROFONANPE's Social and Environmental Policy, referenced in the Accreditation decision;

- The Maldives Project, Social and Environmental Screening Procedure, despite moderate risks being identified;

- $\quad$ The Tuvalu Adaptation Project "detailed stakeholder engagement plan" provided in Annex XIII;

- $\quad$ The CAMP4ASB project Resettlement Policy and Resettlement Framework referred to in the project proposal;

- The "detailed Monitoring and Evaluation plan" mentioned in the Argentina Sustainable Energy Project documentation;

- The CRAVE risk assessment results and the maps of Indigenous Peoples and other local community lands;

- Maps of potential project locations and Native lands (if any will be impacted) on Funafuti prepared for the Tuvalu Adaptation Project;

- $\quad$ The AMAs between the IDB, $\mathrm{Cl}$, and CDB;

- $\quad$ Full accreditation reviews; and

- $\quad$ Funded Activity Agreements (FAAs).

\section{3: Limited Guidance for Financial Intermediaries of Accredited Entities}

Application of safeguards is particularly problematic when funds are moved from AEs to, and through, other Financial Intermediaries (Fls). Shortcomings in this context are notable for resource rights and other related concerns.

In the context of funding through Fls, GCF guidance comes up short in at least three ways. First, it does not clearly indicate what an AE must do to ensure Fls adequately consider and mitigate potential risks. Second, it does not require disclosure of higher-risk subproject information on the GCF website or elsewhere. Finally, it allows the inclusion of unapproved high risk (Category A) subprojects into Category B initiatives supported by Fls. 
The first shortcoming may relate to the failure of the Fund to include key elements of IFC's Policy on Environmental and Social Sustainability and Interpretation Note on Fls when it adopted the interim ESS and Guidance Notes. These documents ${ }^{36}$ describe IFC obligations to ensure Fls avoid and manage risks. In short, this requires Fls to have ESMSs that incorporate relevant PS1 principles and apply PS2 to PS8 requirements to high risk activities (i.e., Category A and $B$ projects). ${ }^{37} \mathrm{GCF}$ guidance does not specifically require the same of AEs, and available evidence suggests not all Fls abide by such measures. ${ }^{38}$

The Caribbean SEF Project is particularly revealing of this "blind spot" in the GCF's approach to safeguards. Although the proposal indicates that IFC's Performance Standards (as well as IDB's and $\left(D^{\prime}\right.$ 's) will be applied to subprojects, including those involving high risk geothermal activities, project documents do not reference an ESMS for the CDB (the acting FI) to ensure that it "can and will" apply requisite Performance Standards. Instead, the project relies on the CDB's Environmental and Social Review Procedure (ESRP) and includes an Environmental and Social Management Report (ESMR) that acknowledges the CDB's limited experience managing high risk geothermal projects, and high risk projects more generally.

Another example of inadequate attention to the ESMS of an FI (to an $\mathrm{AE}$ ) is provided by the World Bank's Climate Adaptation and Mitigation Program for the Aral Sea Basin (CAMP4ASB Project). Although not described as such, this project relies on Fl-type modalities, involving the transfer of funds from the AE (the World Bank) to unaccredited entities, including National Compliance Units (NCUs). The Environmental and Social Management Framework referenced by the proposal focuses on environmental issues with scant attention to social concerns. ${ }^{39} \mathrm{As}$ a result, the extent, nature, and potential impacts of critical social issues, including the capacity of NCUs to address these remains largely unknown. Furthermore, it is unclear whether subproject information will be disclosed on the AE or GCF website. NCU management frameworks note only that Category B subprojects will be "made available to protected affected groups and local NGOs in an easily accessible NCU website." ${ }^{\prime \prime 0}$

By contrast, the South African Project on Micro, Small, and Medium Enterprises (South African MSME Project) is a Category I-2 project that provides a good example of what projects should include. The proposal and safeguards indicate that the intermediaries must have an ESMS, and that such a system should be consistent with IFC standards. It further notes that clients of these intermediaries "will be expected to respect human rights." 


\section{4: Inadequate Protection of Indigenous Peoples', Local Communities', and Rural Women's Rights}

Indigenous Peoples' and local communities' land and resource rights and tenure security are critical to achieving GCF objectives. ${ }^{41}$ However, the current GCF policy framework and interim ESS do not include measures to address, protect, and enhance the customary tenure and resource rights of Indigenous Peoples and local communities under international law, such as ILO 169, UNDRIP, and the VGGT, among others. As reflected in the results of this analysis and described below, nearly all of the reviewed projects lack clear and detailed consideration of community rights-particularly tenure and resource rights. Only one project provides an adequate description of potentially impacted communities and their relationships to land and resources. Projects involving Indigenous Peoples acknowledge tenure concerns and their significance for project success, but fail to articulate measures to address these. Only two of four projects involving AEs lending through Fls commit to addressing tenure issues, but proposed interventions do not present measurable targets.

The rights-based expectations of the Paris Agreement, the important UN-elaborated principles recognizing responsibilities of private business with respect to human rights (the so-called "Ruggie Principles" ${ }^{42}$ ), and other legal precedents should compel the GCF to remedy the absence of relevant human rights provisions in the GCF policy framework. Currently, safeguards are insufficient to ensure compliance with international norms or government obligations vis-à-vis social and environmental protections, such as those articulated in the REDD+ Cancun Safeguards. ${ }^{43}$

\section{Integration of International Human Rights}

GCF safeguards recognize the need to respect human rights, but provisions requiring action on this are weak and limited to two performance standards only. PS1 mentions "Business should respect human rights" 44 and indicates that regular due diligence against the PS "will enable the client to address many relevant human rights issues in its project." ${ }^{45}$ While true to some extent, failure to specify expectations on human rights can also undermine their respect, including the normative weight and implications that follow explicit mention of human rights. ${ }^{46}$

The standard for Indigenous Peoples (PS7) includes an objective to ensure respect for the rights of Indigenous Peoples, ${ }^{47}$ but does not explicitly require adherence to particular rights or rightsbased approaches, nor does it stipulate the necessity of secure rights for the realization of programmatic results. Instead, consistency with international law, including the United Nations Declaration on the Rights of Indigenous Peoples (UNDRIP), is framed as an expectation. ${ }^{48}$ Guidance to PS7 does reflect the need to protect and ensure the rights of indigenous women, ${ }^{49}$ 
but stops short of making this a requirement. These shortcomings are also reflected in projects: key instruments such as the VGGT and UNDRIP are not referenced in any of the reviewed projects, while only two refer to ILO $169 .{ }^{50}$ Failure to clearly reference the relevance and importance of key international commitments in adopted GCF guidance and safeguards is one of the primary justifications for the early adoption of a clear and robust Indigenous Peoples' policy within the GCF.

Admittedly, whether or not projects apply such principles can be difficult to determine, based on available information. For example, UNDP safeguards require project consistency with obligations under international law and further support recognition of Indigenous Peoples' rights, but measures to ensure respect for human rights are not clearly referenced in the Maldives Water Project. The project describes potential impacts on resource rights (e.g., restricted resource access and potential impacts on groundwater through greywater recharge), yet affected individuals and communities, and their relationship to land and resources, are not specifically identified. Measures to mitigate such impacts are not detailed in available documentation. ${ }^{51}$

\section{Balancing National and International Laws Concerning Land and Resource Rights}

A further concern of the current GCF safeguards relates to the customary land and resource rights of Indigenous Peoples and local communities. Interim ESS support only rights "recognized or recognizable" under national law, thus failing to uphold international law. This is problematic for a number of reasons. Depending on local circumstances, national laws and policies may not provide adequate protection for Indigenous Peoples and local communities, or create the enabling environment that will support GCF investments. ${ }^{52}$ Failure to recognize international law can also impair local community rights, or allow projects to unfold in areas marked by unjust marginalization and exploitation of communities. The GCF's emphasis on the need for "Country Ownership" is problematic in this context. Overreliance on national governments to define the scope of land and resource rights can effectively undermine efforts to uphold higher-level standards. In this sense, country ownership and respect for basic human rights should not be confused with government ownership and/or other justification for failed application of higher-level standards.

One such example involves the CRAVE Project in Namibia, which aims to promote "Climate Resilient Agriculture in three of the Vulnerable Extreme northern crop-growing regions." The project focuses entirely on land use activities involving rural farmers, and the project submission makes a brief oblique reference to traditional and indigenous communities. ${ }^{53}$ The environmental and social safeguard assessment (ESS), which was not publicly available but secured by RRI upon request to the GCF, more clearly acknowledges that the San people are 
located within the project area and will be beneficiaries of the project. The ESS states, however, that "project documents have not provided evidence to include presence/absence of indigenous peoples in the process" and, as such, "it is not considered that the IFC scope for 'indigenous peoples' is triggered in this project." ${ }^{54} T$ The project document mentions land and resource rights in passing only, suggesting local user rights are recognized and thus not an issue in the context of the project. Linkages to international law are likewise omitted.

Similarly, the Gambian EbA Project targets communities in decentralized areas with "clear and transparent tenure arrangements, ${ }^{\prime 55}$ but does not explain the process or criteria used to determine the existence of such rights. The proposal cites "decentralized forest management

rights" such as those granted for "Community Forest reserves" as evidence of adequate tenure security. ${ }^{56}$ To its credit, the GCF Board called for a conditional disbursement, based on the "delivery of a letter from the AE (UNEP) confirming that the management rights of the 78 forests where the project will be implemented were transferred to community management." ${ }^{157}$ However, many questions remain unanswered. For example: How do project proponents define secure tenure arrangements? What are the "forest management rights" of communities and how do they relate to other tenure and resource rights? And, are there existing conflicts over rights to these lands and/or use of natural resources?

A similar challenge to the adequacy of GCF safeguards concerns potentially displaced persons. Similar to previous observations, the safeguards for physically or economically displaced peoples or communities (under PS5) apply only to community land and resource rights "recognized or recognizable under national law." While AEs must obtain the free, prior, and informed consent (FPIC) of Indigenous Peoples threatened with possible displacement ${ }^{58}$ from customarily claimed lands and territories within a project's area of influence, application of this principle leaves much to be desired, as discussed in the following section. Fortunately, the standard provides assurances for women's rights, indicating that decision-making processes "should ensure that women's perspectives are obtained and their interests factored into all aspects of resettlement planning and implementation, including as they relate to women's livelihoods." This includes ownership, tenure, and compensation. ${ }^{59}$

\section{Application of Free, Prior, and Informed Consent}

According to IFC PS7 and other related guidance, FPIC is required for activities that either: (1) occur on lands, and/or involve development of natural resources on lands, that are subject to Indigenous Peoples' traditional ownership and customary use; (2) relocate Indigenous Peoples from traditionally used lands and resources or restrict the use of such assets, e.g., through establishment of protected areas; or (3) "significantly impact critical cultural heritage" 
considered "essential to the identity and/or cultural, ceremonial, or spiritual aspects of indigenous peoples' lives." ${ }^{\prime 6}$

FPIC, as a matter of policy and good practice, should help enforce the rights of Indigenous Peoples and local communities to their lands and resources. It is reflected in key international instruments, including UNDRIP, ILO 169, CEDAW, and the VGGT, among others. Invariably, however, interpretation by different actors leads to different forms of application and enforcement, including inconsistencies in the way FPIC is applied by international bodies or initiatives and national-level intermediaries. The GCF faces similar challenges. The few projects that allude to FPIC reveal application tends to be partial at best, either because the "affected people" are not considered indigenous, or because processes for implementing FPIC are not well defined. For example, the Gambian EbA Project mentions FPIC twice but offers no description of its critical importance, what it requires, or how it should be sought. ${ }^{61}$

Hampering efforts to ensure wider application of FPIC is the way the standard is interpreted and applied by the IFC. Related guidance suggests that FPIC should reflect "applicable national laws" and "host country obligations under international law." However, the IFC makes no mention of the need to consider findings from international human rights bodies, including their reviews of consistency of national law with international laws or standards. The discretion left to the project developer in defining a project's "area of influence" and determining whether FPIC applies to a given community can also undermine local rights. To this end, at least four of the reviewed projects, including CRAVE, Caribbean SEF, the Asian Development Bank's Pacific Islands Renewable Energy Investment Program (Pacific RE-Invest Project) and UNDP's Tuvalu Coastal Adaptation Project (Tuvalu Adaptation Project) suggest that FPIC may be required, due to possible involvement of Indigenous Peoples. However, none define whether actions were taken or not to address FPIC.

IFC guidance clearly recognizes that FPIC is a continuous process of engagement, applicable to various aspects of the project/program cycle. However, neither the GCF nor the IFC reminds applicants that securing FPIC once is insufficient for justifying consent over time (e.g., where initial information and understandings were incomplete to support consent for all future activities; when additional activities are undertaken; or when underlying circumstances change). Moreover, the IFC does not provide clear guidance for dealing with changes in expectations over time. ${ }^{62}$ In this analysis, only the South African MSME Project states clearly that FPIC "is not a one-time process that gives everlasting social license to a development." ${ }^{63}$

One of the more notable cases demonstrating the challenges of applying FPIC in the context of GCF investments is the Peru Wetlands Project. This project is said to have raised concerns 
about the capacity of the GCF to ensure the respect of the affected Indigenous Peoples' rights to territories, lands, and resources via effective consultations and FPIC. ${ }^{64}$ The issues that arose around this project were an essential catalyst for increased engagement at the GCF by Indigenous Peoples, and the subsequent development of an Indigenous Peoples' policy that is now under final review. In spite of contradictory evidence by CSOs, the project proponent had argued before the GCF Board that adequate consultations had been conducted and that FPIC was therefore unnecessary. ${ }^{65}$ Yet, video documentation of the consultation process showed that project activities were only partially described, limited attention was given to potential risks, meeting requests from communities were unmet, and women participants faced unreasonable barriers. After CSOs and indigenous groups successfully demonstrated that some 113 communities had not been consulted and the FPIC was essential, ${ }^{66}$ the Board approved the project on the condition that the proponent would: (i) "clarify which indigenous organizations wish to participate in the project and to obtain clear written consent from their representative organizations in order to ensure that the project is only implemented in the territories of the indigenous organizations that have provided their clear consent to the project; and (ii) provide the opportunity for the participating indigenous organizations to take part in project design in dialogue with the accredited entity." ${ }^{67}$ While these conditions have reportedly been fulfilled, supporting documents have yet to be made publicly available. ${ }^{68}$

Evidence drawn from a limited subset of projects shows that the GCF does not apply a consistent and common understanding of FPIC as set out in ILO 169, UNDRIP, and other relevant international instruments. The absence of a stand-alone policy and guidance on the subject, for use by National Designated Authorities (NDAs), AEs, Executing Entities, and financial intermediaries invariably weakens the Fund's ability to effectively apply and enforce this critical principle.

\section{Impacts on Indigenous Peoples', Local Communities', and Women's Rights and Livelihoods}

GCF standards do not require systematic assessments of project impacts on the human rights of communities and women. Instead, the standards note that in "limited high risk circumstances, it may be appropriate for the client to complement its environmental and social risks and impacts identification process with specific human rights due diligence as relevant to the particular business. ${ }^{169}$ When activities risk affecting the lands and resources of Indigenous Peoples and local communities, the environmental and social impact assessment process considers only those rights "recognized or recognizable" under national law. ${ }^{70}$ Land and resource rights under international law and the findings of relevant human rights bodies are not recognized by the GCF. 
Overall, evidence suggests that greater attention is placed on impacts to livelihoods, wherein the "direct or indirect economic, social, cultural and environmental impacts" should be assessed and "further analysis" pursued as necessary "to collect baseline data" on the "environmental and socioeconomic aspects that may be impacted by the project."71 Further, the standard notes that "assessment of land and natural resource use should be gender inclusive and specifically consider women's role in the management and use of these resources."72 Yet, given that the depth and scope of analysis ultimately depends on the applied risk categorization process, the absence of clear criteria and guidance for making objective and verifiable determinations of likely risks brings into question the usefulness of the proposed approach (see Section 3.2 above).

Despite the absence of a GCF requirement for human rights due diligence, four projects nevertheless intend to apply such a standard. The Maldives Water Project and Tuvalu Adaptation Project committed themselves to the application of UNDP standards, which require respect for human rights, and the Madagascar Smallholders Project referenced the use of EIB standards that have similar requirements. The South African MSME Project also requires attention to human rights, with a screening procedure intended to exclude subprojects that could adversely impact tenure or livelihoods. The application of such procedures was not assessed.

Detailed descriptions of local communities potentially impacted by a proposed investment were provided in the Madagascar Smallholders Project only. While multiple ethnic groups with long-standing traditional relationships to land and resources are identified in the project area, along with sacred sites dating back to the $14^{\text {th }}$ and $15^{\text {th }}$ centuries, the project does not examine the idea that these communities, while not self-identifying as "Indigenous," may require recognition and support to protect their unique cultures and livelihoods, per PS7. ${ }^{73}$ As revealed in a recent study of forest communities in Madagascar, "a great many Malagasy peoples live in, have deep cultural ties with, and directly depend on the island's forests." While only one group is formally recognized as indigenous, authors note that policies "should better foster respect for residents' dignity and human rights, including consideration of a broad range of people, regardless of self-identity, who are socially and economically vulnerable because of restricted capacity to assert their interests in a democratic manner."74

GCF assessment requirements for projects involving Indigenous Peoples-to identify, describe, and document traditional uses, tenure systems, and claims to land and resources-are not clearly met in the three relevant direct investment projects reviewed. Two of these (the Peru Wetlands Project and Gambia EbA Project) acknowledge tenure-related concerns and their significance, but fail to document traditional uses and claims, or include clear measures to 
protect communities' customary rights. Similarly, the two Fl projects referencing Indigenous

Peoples (the Argentina Sustainable Energy Project and South Africa MSME Project) commit to meeting related requirement for subprojects, including efforts to conduct in-depth assessments of "land acquisition and resettlement," and develop baseline information on "affected people, land ownership, indigenous people, vulnerable people, cultural resources," and "negotiated agreements" related to tenure where feasible. ${ }^{75}$ Whether and how these intentions were applied was not assessed in this review.

Recently, over 100 Indigenous Peoples and civil society organization made a submission to the GCF for a clearer approach to determining when requirements related to Indigenous Peoples should be applied. ${ }^{76}$ The submission recommends that, at a minimum, the GCF policy should apply to Indigenous Peoples as characterized in Article 1 of ILO Convention $169^{77}$ and draw on the working definition used by the UN to assess a number of variables. ${ }^{78}$

\section{5: Variable Stakeholder Engagement, Benefit Sharing, and Grievance Redress Mechanisms}

The Fund's ESS includes relatively strong requirements for consultation and participation of local communities, benefit sharing, and grievance redress. Project proponents are required to identify and consult at-risk communities, collect their views on potential impacts and mitigation measures, ${ }^{79}$ and when "potentially significant adverse impacts" are identified, communities must be engaged through "Informed Consultation and Participation" or FPIC in certain conditions (see discussion above). ${ }^{80}$ Additionally, communities are required to be informed of the purpose, nature, and scale of the project; duration of activities; potential risks and impacts; proposed mitigation measures; stakeholder engagement processes; grievance mechanisms; and benefit-sharing approaches. ${ }^{81}$

As discussed in the following sections, however, most project documents lack detailed information on the proposed approaches to consultation, benefit sharing, and grievance redress. Four project proposals presented well-defined consultation processes; three described how grievances would be addressed; and six discussed benefit-sharing modalities. Like other environmental and social considerations, because requirements within the ESS are proportional to identified risks and impacts, a mischaracterization from high to low ultimately results in weaker obligations for engagement and follow up by the project proponent. ${ }^{82} \mathrm{As}$ a result, lower risk projects tend not to address the need for consultation, benefit sharing, and grievance redress with the same degree of rigor as higher risk initiatives. Similarly, limited understanding of stated requirements can also lead to weaker levels of application, such as when the need for stakeholder consultations is viewed as a post-approval necessity only. 


\section{Limited Community Participation in Project Design, Appraisal, and Implementation}

The "Initial Best Practices for Country Coordination and Multistakeholder Engagement" annex ${ }^{83}$ states that stakeholder engagement and country coordination are "critical" for the preparation of funding proposals, the development of a performance management frameworks, and ensuring alignment with relevant GCF environmental and social safeguards, such as those related to stakeholder engagement and information disclosure. Guidelines for the selection and establishment of countries' National Designated Authorities (NDAs) and Focal Points also focus on the "capacity to facilitate and coordinate country coordination mechanisms and multistakeholder engagement for country consultations." While projects generally acknowledge the need for community participation in the design, appraisal, and implementation of projects, such processes tend to be poorly defined, and few offer clear descriptions of how implementation will proceed and who will be involved (i.e., the communities impacted by the initiative). Factors affecting community participation include inadequate identification of communities potentially impacted and the relatively limited transparency of project submissions in terms of public disclosure of information.

As noted elsewhere, only the Madagascar Smallholders Project offered detailed descriptions of the potentially impacted communities. Others, such as the Maldives Water Project, were required by the GCF Board to include an implementation road map to actively involve communities. Such plans, however, are not always required by the Fund, nor elaborated in the proposals themselves. This range of community participation processes can be seen in the following examples:

- The Gambian EbA Project acknowledges the importance of stakeholder engagement, and indicates a need to involve local community stakeholders in relevant decisionmaking processes (e.g., Village Development Committees and Forest Management Committees). However, the composition, representativeness (including gender inclusiveness), and level of involvement of these local committees in project decisionmaking arenas-such as the Project Steering Committee-remain undefined.

- The Peru Wetlands Project indicates that key decisions will be made by a Steering Committee that includes only one Indigenous Peoples' representative. Additional references to the involvement of Peru's Forest Investment Programme (FIP) are likewise unspecified;

- The Namibia CRAVE Project broadly notes that "local governance and traditional authorities ... will be consulted and informed" in the selection of activities, but fails to specify how. 
- The Caribbean SEF Project, for which the Caribbean Development Bank is an Fl, requires its funded entities to develop Stakeholder Engagement Plans, but the Bank's ESMP provides little detail and guidance on stakeholder engagement.

- The Madagascar Smallholders Project is the one outlier, providing a detailed description of how consultation processes will occur.

Some project proposals reflect a perception that robust engagements with local communities and stakeholders can occur after project design and approval. While engagement should continue following approval, lessons learned from the past several decades of development assistance clearly show that community participation in the planning and design phases is equally if not more important. For example:

- The CAMP4ASB Project, while providing a focus on local community efforts to adapt to climate change (e.g., by supporting community adoption of climate resilient agriculture), does not indicate whether and how the targeted subsistence farmers were consulted during project design, only that local government and traditional authorities will eventually be consulted. Despite an ITAP (Independent Technical Assessment Panel) recommendation that the Board not fund the project, in part due to the "lack of real community consultations, ${ }^{184}$ funding was nevertheless conditioned on the basis of stakeholder consultations "by the accredited entity during the design of the project." ${ }^{85}$

- The Gambian EbA Project to build the climate resilience of rural communities does not provide a substantive description of the targeted communities and their engagement prior to project approval. The proposed stakeholder engagement strategy for the implementation phase is referenced, but not made public.

- The Tuvalu Adaptation Project refers to visits to all of the country's islands in 2007-2008, with more than 50 percent of the population engaged. It states that "while no on the ground consultation has been undertaken at this time, it is expected that consultation with affected communities will be undertaken when the detail design of the project is available" and "awareness campaigns on coastal protection" are undertaken to improve community-level understanding and endorsement of the proposed interventions. Consultation "fatigue" was cited as an issue, with a plan to clearly spell out the implementation schedule, expectations, and community engagement requirements during initial island visits. ${ }^{86}$

Arguably, in situations where consultations are inadequate, but project proponents receive approval for their initiatives, the incentive to heed local community concerns regarding possible flaws in the project design and/or suggestions to modify or reorient a project will understandably be limited. Challenges to project success under such conditions are more likely 
to emerge, as in the case of the Peru Wetlands Project, where indigenous groups are challenging the project in part due to poor consultation processes. ${ }^{87}$

In contrast, the Madagascar Smallholders and South African MSME projects offer good examples of effective and transparent consultations. As noted earlier, the Madagascar Smallholders Project proposal provides a relatively detailed description of need and processes for future engagement. The South African MSME Project emphasizes the need for participation of local affected communities in decision-making processes, defining and describing requirements for "effective consultation."

\section{Equitable Benefit Sharing Arrangements}

The approaches to benefit sharing amongst GCF projects vary from no arrangements (e.g., the Namibia CRAVE Project) to comprehensive arrangements, such as the CAMP4ASB Project and Tuvalu Adaptation Project, which reference data-focused approaches to ensuring equitable benefit sharing, with plans to collect disaggregated data to understand beneficiaries by gender.

Overall, most projects include clear reference to benefit-sharing schemes. Gender considerations linked to benefit sharing are included in at least nine projects. ${ }^{88} \mathrm{Non}$-financial benefits are highlighted in the Pacific RE-Invest Project submission (access to electricity and reduced air pollution), the Caribbean SEF Project (reduced dependence on fossil fuels), and the Gambian EbA Project (increased food security and employment opportunities). Only one project refers to potential financial benefits-the Peru Wetlands Project-via existing REDD+ results-based payment schemes. However, it goes on to state that in the unlikely event that revenues from emission reductions would be achieved, these would not be shared with local communities. ${ }^{89}$

\section{Incomplete Grievance Redress and Dispute Resolution Mechanisms}

The GCF has an Independent Redress Mechanism (IRM) that serves three objectives. The first is a "compliance" function relative to all GCF policies, including social and environmental standards. The second is a problem-solving function to resolve issues before a complaint investigation is initiated. The third is an adjudication function to field requests from developing countries for reconsideration of funding proposal decisions..$^{90}$

Regardless of the mechanism used, adequate redress for infringements of rights can be achieved only if called for by the existing policies and safeguards. Hence, if the policy framework of the GCF or AE is lacking in this regard, it follows that the "scope" of any IRM will also be limited. Dispute resolution mechanisms may or may not provide redress for rights infringements; such mechanisms are centered on agreements between parties, and do not 
necessarily involve agreements on rights. Matters such as locality, access, legal representation, and costs are also critical components of power dynamics associated with any dispute resolution, wherein rural communities are often at a distinct disadvantage.

The mechanisms used by the AEs analyzed in this study ranged from well documented approaches (e.g., the World Bank Group's Inspection Panel for public sector lending and Compliance Advisor Ombudsman for private lending) to newly established and untested frameworks (e.g., the CDB's IRM). ${ }^{91}$ Hence, the adequacy of IRMs varied considerably across the sample of reviewed projects. To this end, important information related to access, process, and procedure was found missing from the descriptions of six project-level grievance redress mechanisms:

- The Maldives Water Project mentions a mechanism, but provides no descriptions of it;

- PROFONANPE's website, (relating to the Peru Wetlands Project) includes a complaint form, but does not describe the process for responding to them or key principles related to transparency, independence and timeliness;

- The CDB mechanism, as described on its website, provides no operating procedures;

- The Tuvalu Adaptation Project does not describe how concerns will be investigated and what possible responses might be; ${ }^{92}$

- The Madagascar Smallholders Project's IRM does not articulate key principles such as transparency and independence; and

- Project documentation from CAMP4ASB lacked clear reference to the principles and criteria underpinning the development and implementation of its IRM-a surprising observation given the World Bank Group's extensive experience with project-level grievances and grievance mechanisms. ${ }^{93}$

Four of the reviewed initiatives lacked project-level grievance or accountability mechanisms, though two indicated intentions to develop such mechanisms in the near future:

- The CRAVE Project provided no reference to an IRM ${ }^{94 ;}$

- The Gambian EbA Project document indicates that it will "borrow from the ongoing approach used by the Department of Forestry;" ${ }^{\prime 95}$ and

- The CAMP4ASB Project briefly notes that a "feedback mechanism will be designed to process complaints, concerns, and questions from stakeholders at different levels (regional to local), with a view to resolving $100 \%$ of these concerns. ${ }^{\prime 96}$

And only three initiatives presented clearly defined and accessible project-level accountability mechanisms: the South African MSMEs Project, the Argentina Sustainable Energy Project, ${ }^{97}$ and the Pacific RE-Invest Project. ${ }^{98}$ 


\section{Variable Safeguards, Stakeholder Engagement, and Benefit Monitoring Approaches}

Plans to monitor the implementation of social and environmental safeguards, stakeholder engagement, and benefit sharing with communities varied across the sample of reviewed projects, with examples of both strong and weak integration.

Transparent and independent mechanisms for monitoring social and environmental impacts and the application of safeguards were observed in four of the 11 reviewed project proposals. The Madagascar Smallholders Project and the South African MSME Project presented the strongest commitments, with detailed intentions to monitor both public and private sector interventions in the former, ${ }^{99}$ and carefully apply safeguards in the latter, using the South African government's monitoring system ${ }^{100}$ to ensure compliance. ${ }^{101}$ The Caribbean Geothermal Project and the Argentina Sustainable Energy Project also provide clear monitoring timeframes and descriptions of how safeguards will be monitored. By contrast, the Peru Wetlands Project, Maldives Water Project, The Gambian EbA Project, CAMP4ASB Project and Tuvalu Adaptation Project all had weak to non-existent measures to monitor safeguards. The case of the CAMP4ASB Project is particularly concerning. It notes that the National Compliance Units will ensure compliance with the WBG safeguards only if and when they are contrary to national practice. ${ }^{102}$

While five of the reviewed projects do not specify plans for monitoring stakeholder engagement, ${ }^{103}$ all of the proposals acknowledge a need to monitor project benefits and provide an approach for doing so. The Tuvalu Adaptation Project and the CAMP4ASB Project both describe plans to collect data disaggregated by gender to ensure that women benefit from the project. The importance of monitoring benefits for women was also emphasized in the South African MSME Project, ${ }^{104}$ Pacific RE-Invest Project, and the Madagascar Smallholders Project. The Tuvalu Adaptation Project even indicates an intent to use a "community scorecard" and participatory video tool to monitor activities. ${ }^{105}$ The Maldives Water Project and The Gambian EbA Project also commit to robust approaches to monitoring benefits. ${ }^{106}$ 


\section{Conclusions}

The GCF is seeking to promote a paradigm shift in developing countries-to reorient development toward a low-emission and climate-resilient focus and approach. This paradigm shift is challenged by GCF's current policies and frameworks, especially those relating to the rights of Indigenous Peoples, local communities, and rural women. As described above, the policies-on paper and in practice-are not adequately engaging with, or acknowledging and supporting the contributions of Indigenous Peoples and local communities to the Fund's lowemission and climate-resilient objectives. This challenge is further exacerbated by the GCF's seemingly limited ability to exert positive pressure on AEs, NDAs, and others, including compliance with established standards and safeguards.

Respect for the rights of Indigenous Peoples and local communities should be of particular importance to the GCF now that the Paris Agreement has been finalized and entered into force. The Agreement contains important provisions relating to human rights and Indigenous Peoples and the positive contribution of traditional knowledge, but evidence drawn from this review suggests that the GCF has yet to revise its policies and guidance to ensure consistency with these expectations. Given the need to rapidly scale-up action to maintain a mean global temperature rise well below 2 or 1.5 degrees Celsius, the need to urgently address these issues cannot be overemphasized.

Analysis of the 11 selected projects reveals problematic concerns regarding the adequacy of current GCF safeguards for the recognition and protection of Indigenous Peoples' and local communities' land and resource rights, as well as distinct weaknesses in the design of master agreements with AEs, which allow the use of weaker safeguards than those of the GCF. Failure to apply GCF safeguards and disclosure requirements when funds are moved from AEs through Fls was also noted as a drawback to effective implementation of endorsed standards and principles.

One of the most notable obstacles to the application of safeguards relates to the identification and categorization of risks. The miscategorization of risk can have significant "knock on" effects when high risk initiatives are graded lower, since all other requirements (e.g., consultation, transparency, monitoring, and measures to address impacts) are likewise reduced. When requirements for projects impacting Indigenous Peoples and local communities are minimized, opportunities for just development and the success of the initiative itself are also jeopardized. Factors affecting the ability of AEs to appropriately categorize risks include the lack of clear and enforceable guidance from the GCF to define, identify, and monitor risks, as well as failure to require public disclosure of information justifying a given risk assessment category. 
Assessments of potential impacts on the rights and livelihoods of Indigenous Peoples, local communities and rural women are not required under current GCF standards. Only in "limited high risk circumstances" does the GCF consider that "it may be appropriate for the client to complement its environmental and social risks and impacts identification process with specific human rights due diligence as relevant to the particular business." Weak attention to human rights due diligence is problematic for the pursuit of GCF objectives, particularly in a context of abundant guidance (e.g., UN Guiding Principles on Business and Human Rights, the VGGT) on which to build on.

As currently formulated, the GCF policy framework fails to recognize or protect the customary tenure and resource rights of Indigenous Peoples and local communities under international law. Because the GCF supports only those rights "recognized or recognizable" under national law, and consistency with international law (i.e., PS7) is framed as an "expectation" only, most projects fail to recognize the relevance of principles embodied in key instruments such as UNDRIP and ILO169.

Similarly, requirements for free, prior, and informed consent are only weakly reflected in GCF Safeguards/Policy Framework. As result, only one of the projects analyzed detailed the application of FPIC in both the design and implementation phases. Lacking in the GCF's approach is a clear and common understanding of FPIC, as set out in ILO 169 and UNDRIP, the absence of a stand-alone Indigenous Peoples' policy, and limited guidance on the importance and application of FPIC for use by AEs, Executing Entities, the Secretariat, the Board, ITAP, and all other stakeholders.

Process-oriented requirements for stakeholder engagement, benefit sharing, grievance/redress mechanisms, and project monitoring showed mixed levels of implementation. While all projects acknowledge the importance of stakeholder engagement and consultations, few demonstrated robust or timely consultations. More often than not, projects were designed without clear input from the communities that are likely to be impacted or benefit from investments. However, most projects included relatively clear benefit-sharing schemes with stated concerns for gender equity, and the majority referenced the existence of a grievance mechanism, though only three clearly defined their approaches and made them accessible. Monitoring frameworks likewise varied, with sparing attention to environmental and social impacts and safeguards, compared with efforts to monitor the distribution of project benefits. 


\section{Recommendations}

The GCF is an evolving and growing entity venturing into new territory. As such, its policies need to be revisited, altered, and improved over time. Critically, the review and replacement of interim environmental and social safeguards, borrowed from the IFC, offers a significant opportunity to revise and update the GCF's own standards, processes, and tools. As highlighted in this report, there are a number of gaps and weaknesses that stand to hamper the Fund's ability to achieve its desired ends. Going forward, the GCF's Board and Secretariat will need to carefully consider and address the following recommendations to achieve long lasting positive impacts across the developing world:

1. Establish a rights-based approach to climate change investments (taking into account the joint responsibilities of governments and the private sector), grounded in the development of a GCF Human Rights Policy and mainstreaming of international human rights across its policies, projects, and programs.

2. Accelerate the development and implementation of new safeguards that:

a. Address the land and resource rights of Indigenous Peoples, local communities, and rural women in a manner consistent with international law;

b. Ensure that Fls to AEs have an Environmental and Social Management System that incorporates all relevant safeguards and standards, providing that risks are appropriately identified, managed, or avoided, and that GCF requirements for disclosure are likewise applied to FI subprojects;

c. Require AEs to apply standards and safeguards that are consistent with international law and substantively equivalent to those endorsed by the GCF.

\section{Adopt a stand-alone policy on Indigenous Peoples that:}

a. Recognizes the distinct attributes of Indigenous Peoples as characterized in Article 1 of ILO Convention 169 and the working definition used by the UN;

b. Defines FPIC as an iterative process, requiring Indigenous Peoples' and local communities' consent before any GCF-funded initiatives are approved or initiated, based on their own independent deliberations and collective decisionmaking processes, customs, values, and norms, and on the basis of complete information provided in a manner that is understood by them, inclusive and free of coercion or intimidation;

c. Provides clear guidance to support the application of FPIC and benefit sharing, recognition of traditional land management systems and traditional knowledge 
systems, and engagement of Indigenous Peoples-defined by guidance developed in consultation with Indigenous Peoples and local communities.

4. Until new environmental and social standards are adopted, require:

a. The public disclosure of detailed diagnostic comparisons of GCF and AE standards, with descriptions of all identified shortcomings and risk mitigation measures;

b. The application of GCF standards for all AEs that do not wish to undergo a detailed diagnostic comparison. This should include guidance to ensure GCF standards are met by all entities engaged in a project;

c. The use of methodologies already applied elsewhere to assess projects on the subject of tenure, such as those developed in the FAO Voluntary Guidelines for the Responsible Governance of Tenure.

5. Establish clear and enforceable guidance on risk due diligence, applicable to NDAs, AEs, and the GCF, that ensures:

a. Assessment of potential risks prior to mitigation, and agreement on measures to mitigate risks prior to Board approval;

b. Identification and characterization of all project risks, including those related to infringements on Indigenous Peoples', local communities' and women' rights;

c. Public disclosure of all risks, including justification for proposed categorizationsupported by GCF guidance describing the necessary level of information.

6. Develop clear and enforceable guidance related to:

a. Stakeholder engagement processes to ensure the full and effective participation of all relevant stakeholders;

b. Gender assessments and action plans;

c. Benefit sharing agreements;

d. Grievance redress mechanisms, including issues related to access, transparency, and process.

7. Ensure that all environmental and social reports, as well as project-specific gender analyses and action plans are publicly available on the GCF website under each project sub-site; and

8. Strengthen monitoring requirements related to safeguards implementation, impacts, and distribution of benefits (both financial and non-financial) that rely less on self-reporting and more on participatory processes. 
${ }^{1}$ To be approved by the GCF Board in July 2017. See: Work programme of the Secretariat for 2017 and adjusted administrative budget (GCF/B.16/21/Rev.01).

${ }^{2}$ REDD+ refers to "reducing emissions from deforestation and forest degradation and the role of conservation, sustainable management of forests and enhancement of forest carbon stocks."

${ }^{3}$ See: The Paris Agreement.

${ }^{4}$ See GCF Governing Instrument, section XIII. STAKEHOLDER INPUT AND PARTICIPATION, para 71. “The Board will develop mechanisms to promote the input and participation of stakeholders, including private-sector actors, civil society organizations, vulnerable groups, women and indigenous peoples, in the design, development and implementation of the strategies and activities to be financed by the Fund"

${ }^{5}$ See GCF Environmental and Social Safeguards here.

${ }^{6}$ See Environmental and Social Management System here.

7 The GCF Independent Redress Mechanism (IRM) responds to complaints by people who feel they have been adversely affected by GCF projects or programmes failing to implement GCF operational policies and procedures. This includes allegations of a failure to follow adequate environmental and social safeguards. The IRM can also accept requests by developing country National Designated Authorities, or focal points, for the GCF Board to reconsider funding proposals which the GCF has rejected.

${ }^{8}$ See 2017 GCF Secretariat work programme here.

${ }^{9}$ See Decisions of the Board - Seventh Meeting of the Board (GCF/B.07/11), p. 16-17. Initial GCF decisions addressing use of IFC standards require AEs to manage risks "in accordance with the Fund's interim ESS" through the relevant executing entity(ies), and AEs are required to "have the capacity and a system for screening funding proposal ... to determine if any potential inconsistencies with the Fund's interim ESS are insurmountable..."

10 See GCF Template accreditation master agreement (AMA Template, GCF/B.12/32) p. 145. Accordingly, an "Accredited Entity covenants that it shall at all times comply, and where applicable shall impose such compliance by the Executing Entity, (i) with its own rules, policies and procedures that should enable it to comply (emphasis added) with the Fund's Standards, policies and procedures to the extent and scope of its Accreditation.

${ }^{11}$ See Guidelines for the Operationalization of the Fit-for-Purpose Accreditation Approach (GCF/B.08/02), p. 17. Annex IV, "Key institutional capacity elements to be assessed during the accreditation process" states that the applicant's "policy should state the E\&S standards the entity adheres to" and "the policy should be consistent with the Performance Standards." It also notes that technical staff must have the "skills and experience necessary to understand and ensure implementation of PS 1-8."

${ }^{12}$ See Consideration of accreditation proposals (GCF/B.14/10), p. 12 and GCF Accreditation checklist.

13 Project submission (p. 47) states that "The project will make use of existing social and environmental safeguards that are applied in terms of national policies on decentralized NRM and forest management to ensure that no negative unintended consequences occur as a result of the project's activities. The results of the 
ESERN tool are included as Annex E." Project submission (p. 51, para 140) also notes: “The proposed approach to identifying communities to participate in the project's activities will borrow from the ongoing approach used by Department of Forestry to identify potential Community Forestry Committees. This includes provisions such as minimum standards for establishing mechanisms for conflict resolution, registry of disputes and complaints, and other measures to ensure that the project's activities are transparent and adhere to the principles of FPIC (free, prior, and Informed Consent)."

${ }^{14}$ RRI secured the ESERN from the GCF after a request to the GCF for this document. Thematic areas referenced in this screening procedure overlap significantly with GCF's ESS thematic areas, including 'Indigenous Peoples' and 'Cultural Heritage,' as well as the 'Human Rights Principle' and 'Gender Equity.' Nevertheless, as noted in our review of the project, responses to the screening questions raise concerns.

${ }^{15}$ See Decisions of the Board - Fourteenth Meeting of the Board (GCF/B.14/17), p. 92.

${ }^{16}$ CSOs have requested greater transparency and participation in this process, including disclosure of documentation more than 21 days prior to Board meeting deliberations, and attention to third party (e.g., affected communities) assessments of implementation records.

17 IFC PS 1 para. 29 - "the client will provide Affected Communities with access to relevant information." See, also, FN 26, "Depending on the scale of the project and significance of the risks and impacts, relevant documents could range from full assessments and action plans, e.g., Stakeholder Engagement Plan, Resettlement Action Plans, etc. to easy-to-understand summaries of key issues and commitments ..."

${ }^{18}$ IFC PS 1, para. 25 "The nature, frequency, and level of effort of stakeholder engagement may vary considerably and will be commensurate with the project's risk and adverse impacts..." And para. 27 "Stakeholder Engagement Plan is scaled to the project risks and impacts....and be tailored to the characteristics and interests of the Affected Communities. Where applicable, the Stakeholder Engagement Plan will include differentiated measures ... When the stakeholder engagement process depends substantially on community representatives, the client will make every reasonable effort to verify..."

19 IFC PS 1, para. 5, "The client ... will establish and maintain an ESMS appropriate to the nature and scale of the project and commensurate with the level of its environmental and social risks and impacts." And GN7. The level of detail and complexity of the social and environment management system and the resources devoted to it should depend on the level of impacts and risks of the project to be financed, and the size and nature of the client's organization. A satisfactory management system appropriate to the nature and scale of the project and commensurate with the level of environmental and social risks and impacts is required. See also Accreditation checklist, p 100.

${ }^{20}$ Note, as well, that for Category C projects the public does not receive any due diligence information or the prior notice that exists for Category A/I-1 projects (i.e., notice provided by disclosure of the ESS 120 days prior to Board consideration of the submission), and Category B/I-2 projects (i.e., notice provided by disclosure of the ESS 30 days prior to Board consideration of the submission).

${ }^{21}$ The GCF Environmental and Social Management System (Draft for Consultation, 15 December 2016), p. 17, notes that risks and impacts are assessed at the "pre-mitigation stage." The IFC Policy notes that "Inherent environmental and social risk is the environmental and social risk related to generic aspects of an industrial sector or commercial activity without consideration of management or mitigation measures."

22 Project documentation (p. 58) acknowledges the long fight of indigenous communities to gain legal tenure for their territories.

${ }^{23}$ See project submission, p. 13. 
${ }^{24}$ See project submission, p 93. Despite a failure to acknowledge that PS 5 applies, the proposal states that "the project will develop guidelines for social safeguards implementation, including indigenous land acquisition and involuntary resettlement." Economic displacement can occur if consent has not been obtained in an adequate way (including from the appropriate communities or representatives of communities) for a change in how resources are used, or for creation of a protected area impacting territories. On p. 51, the submission states: “PS 5. Land acquisition and involuntary resettlement. The project will not generate the displacement of indigenous communities. Instead, it will strengthen legal security by promoting land titling and land-use planning. It seeks the sustainable use of, and unrestricted access to, natural resources in the province, without discriminating between indigenous and non-indigenous peoples. There is a possibility that non-indigenous peoples and persons from outside the territory may inhabit the same territory as project beneficiaries. In these cases, the project will develop a policy of intercultural interaction as is currently being implemented in ACAs."

${ }^{25}$ See project submission, p. 47. See also p. 35, para. 94. Other statements also clearly indicate significant risks, including the following: "In consideration of the complexities of customary land tenure systems in The Gambia, the project's approach to prioritizing communities with formal access rights to CF and CPA areas will minimize the risks related to uncertainties or conflicts over land tenure." And "Social tensions may arise as existing power relations within the community might disrupt equal opportunities to develop a nature-based business."

${ }^{26}$ Currently, Category C projects are not required to prepare or report on Environmental and Social Action Plans. See Guidelines for the Operationalization of the Fit-for-Purpose Accreditation Approach (GCF/B.08/02), Annex IV: Key institutional capacity elements to be assessed during the accreditation process, p. 17.

27 Instead of developing initial baseline information to mitigate potential risks, the Peruvian project proposal, for example, indicates that "A gender-sensitive social analysis will be developed in the first year of the Project, in order to examine the roles of women and men, according to their responsibilities, access, use and control over resources; as well as the problems, needs, opportunities and benefits obtained by each role. This analysis will allow Profonanpe's Project Management Unit, to establish an appropriate strategy to gradually incorporate women in project activities."

${ }^{28}$ IFC PS 7, para. 31. In addition, where a proposed business activity triggers PS 7 requirement for FPIC of Indigenous Peoples, IFC will undertake an in-depth review of the process conducted by the client as part of its environmental and social due diligence.

${ }^{29}$ See IFC Guidance Notes, p. 6.

${ }^{30}$ See project submission, p. 13.

${ }^{31}$ See project submission, p. 57. Note that this is described as medium risk: "Political risk arising from the indigenous communities' registration and land titling, including potential conflict between different groups, and the inability of the independent Redress Mechanism to solve conflicts in a timely manner. If these risks were to materialize, they would affect not only the project, but through legal and reputational risks, both the accredited entity and the GCF."

32 See Guidelines for the Operationalization of the Fit-for-purpose Accreditation Approach, Annex III (GCF/B.08/02): Examples of illustrative types of activities that could be in each risk category. "Projects which are planned to be carried out in sensitive locations or are likely to have a perceptible impact on such locations, even if the project category does not appear in this list. Such sensitive locations include, inter alia, national parks and other protected areas identified by national or international law, and other sensitive locations of international, national or regional importance, such as wetlands, forests with high biodiversity value, areas of archaeological or cultural significance, and areas of importance for Indigenous Peoples or other vulnerable groups." 
${ }_{33}$ World Bank. 2016. Inspection Panel: Indigenous peoples. Emerging Lessons; no. 2. Washington, DC: World Bank Group.

${ }^{34}$ The Funded Activity Agreement, which was not publicly available but secured by RRI in June 2017 after a request to the GCF for this and other documents, indicates that PROFONANPE must provide "clear written consent" of the representative organizations of Indigenous Peoples as a condition for funding, to "ensure that the Project is only implemented in the territories of the indigenous organizations that have provided their clear consent to the Project." PROFONANPE must also provide evidence that Indigenous Peoples were provided an opportunity to participate in the design of the project. It is not clear if the required documents have been provided. Without a full, clear description of lands and resources claimed by Indigenous Peoples, and a clear description of how FPIC must be sought to ensure consistency with international law, the submission and subsequent project documents do not provide adequate assurances that rights will be met in a manner consistent with international law.

35 The project submission suggests that activities such as environment management plans and biobusinesses must be developed with and meet the approval of the government, and that noncompliance with these plans by Indigenous Peoples could result in the loss of rights and responsibility to manage their territories. As stated on page 24: "Large areas will be under government-approved and established operational management plans under the tutelage of community organizations responsible for management, surveillance and monitoring. Newcomers and other potential users will need to negotiate with the communities to gain access to land or any other resource. The main incentives for managing the territories in a sustainable manner-the entrusted authority to manage the area, and the income-generating bio-businesses-will remain after the end of the project. It is argued that the indigenous communities will comply with the approved management plans so as not to concede this prerogative."

36 See IFC Interpretation Note on Financial Intermediaries.

37 The IFC Policy on Environmental and Social Sustainability, paras. 33- 35 note that "FI clients are required to develop and operate an ESMS that is commensurate with the level of environmental and social risks in its portfolio, and prospective business activities. The ESMS should incorporate relevant principles of PS 1 through its engagement with Fls, IFC supports the capacity development of the banking and financial sector to manage environmental and social risks. This is achieved in part through the development and implementation of an ESMS, and by enhancing FIs' in-house capacity for day-to-day management of portfolio risks, including environmental and social risk."

${ }^{38}$ The low capacity of some Fls and their lack of experience in assessing risks and implementing safeguards has been raised by both the GCF's Independent Technical Advisory Panel (ITAP) and by CSOs.

39 The project submission, p. 52, indicates that an Environmental and Social Management Framework "has been designed to guide the sub-investments Environmental Assessment," though the referenced document on file at the World Bank InfoShop is clearly limited to the environment (i.e., the Central Asia, Climate Adaptation and Mitigation Program for the Aral Sea Basin, Environmental Management Framework: Volume III, Republic of Tajikistan).

${ }^{40}$ See Tajikistan Environmental Management Framework, Volume III, p. 37.

${ }^{41}$ See: Stevens, C.et al., 2014. Securing Rights, Combating Climate Change: How Strengthening Community Forest Rights Mitigates Climate Change. Washington, DC: RRI and WRI; RRI 2014. Recognizing Indigenous and Community Rights: Priority Steps to Advance Development and Mitigate Climate Change. Washington, DC: RRI.; Rights and Resources Initiative, Woods Hole Research Center and World Resources Institute. 2016. "Towards a Global Baseline of Carbon Storage in Collective Lands." Washington, DC: RRI. 
42 United Nations Human Rights Office of the High Commissioner. 2011. Guiding Principles on Business and Human Rights. New York and Geneva: United Nations.

${ }^{43}$ The REDD+ Cancun Safeguards call on all parties to demonstrate "respect for the knowledge and rights of indigenous peoples and members of local communities, by taking into account relevant international obligations, national circumstances and laws, and noting that the United Nations General Assembly has adopted the United Nations Declaration on the Rights of Indigenous Peoples." See Decision 1.CP/16, Appendix 1, paragraph 2(c).

${ }^{44}$ See IFC PS 1, p. 1. See also PS 1 FN 12, which notes, "In limited high-risk circumstances, it may be appropriate for the client to complement its environmental and social risks and impacts identification process with specific human rights due diligence as relevant to the particular business."

45 IFC PS 1, para 3 notes, "Due diligence against these Performance Standards will enable the client to address many relevant human rights issues in its project."

${ }^{46}$ See Report of the Special Rapporteur on extreme poverty and human rights, UN General Assembly, 4 August, 2015, p. 19..As noted by Philip Alston, UN Special Rapporteur on extreme poverty and human rights, in his critique of World Bank standards, "the use of a human rights framework and discourse actually makes an enormous difference, ... Human rights provides a context and a detailed and balanced framework; it invokes the specific legal obligations that States have agreed upon in the various human rights treaties; it emphasizes that certain values are non-negotiable; it brings a degree of normative certainty; and it brings into the discussion the carefully negotiated elaborations of the meaning of specific rights that have emerged from decades of reflection, discussion and adjudication. Even more importantly, the language of rights recognizes the dignity and agency of all individuals (regardless of race, gender, social status, age, disability or any other distinguishing factor) and it is intentionally empowering."

${ }^{47}$ See IFC PS 7, Objectives, p. 1.

48 See IFC PS 7, p. 2, GN1: "IFC recognizes that key United Nations (UN) Human Rights Conventions (see Bibliography) form the core of international instruments that provide the rights framework for members of the world's Indigenous Peoples... In addition, various declarations and resolutions address rights of Indigenous Peoples, including the UN Declaration on the Rights of Indigenous Peoples (2007). While such instruments address the responsibilities of states, it is increasingly expected that private sector companies conduct their affairs in a way that would uphold these rights and not interfere with states' obligations under these instruments. It is in recognition of this emerging business environment that private sector projects are increasingly expected to foster full respect for the human rights, dignity, aspirations, cultures, and customary livelihoods of Indigenous Peoples."

${ }^{49}$ See IFC PS7, p. 7, GN16. "The engagement process will ... be cognizant of ... The need to protect and ensure the legal rights of indigenous women"

${ }^{50}$ See the South African MSMEs Project (FP029) and the Madagascar Smallholders Project (FP026).

51 Project submission, p. 21

52 RRI. 2015. Who Owns the World's Land? A global baseline of formally recognized indigenous and community land rights. Washington, DC: RRI; RRI. 2014. What Future for Reform? Progress and slowdown in forest tenure reform since 2002. Washington, DC: RRI. 
${ }^{53}$ See project submission, p. 59. An oblique reference to Indigenous Peoples is provided in the brief Environmental and Social Assessment section, which indicates, "All activities will be implemented either on existing or unproductive or degraded farming lands that are already utilised (with recognized user rights) by local people who have acquired land as part of the Traditional Authority Act, Communal Land and Commercial land Resettlement Acts.... deliberate discrimination will occur to ensure that the most vulnerable people, households and indigenous groups benefit."

${ }^{54}$ Environmental and Social Safeguard Assessment, p. 40-41

${ }^{55}$ See project submission, p. 47.

${ }^{56}$ See project submission, p. 8.

${ }^{57}$ See GCF Decisions of the Board - Thirteenth meeting of the Board (GCF/B.13/32/Rev.01), p. 77.

58 IFC PS5, para 1 defines economic displacement as loss of assets or access to assets that leads to loss of income sources or other means of livelihood.

59 IFC PS5, FN 16 states: “The consultation process should ensure that women's perspectives are obtained and their interests factored into all aspects of resettlement planning and implementation. Addressing livelihood impacts may require intra-household analysis in cases where women's and men's livelihoods are affected differently. Women's and men's preferences in terms of compensation mechanisms, such as compensation in kind rather than in cash, should be explored." PS 5, FN 17 states: "Documentation of ownership or occupancy and compensation arrangements should be issued in the names of both spouses or heads of households, and other resettlement assistance, such as skills training, access to credit, and job opportunities, should be equally available to women and adapted to their needs. Where national law and tenure systems do not recognize the rights of women to hold or contract in property, measures should be considered to provide women as much protection as possible with the objective to achieve equity with men."

${ }^{60}$ IFC PS7, para. 11 states "... the client will obtain the FPIC of the Affected Communities of the Indigenous Peoples in the circumstances described in paragraphs 13-17 of this Performance Standard."

61 Project submission, p. 52, para 144 states: “The project's EbA interventions will not be sustained in the long term in the absence of community support and 'buy-in'. Consequently, the project will maintain the principles of FPIC (Free Prior Informed Consent) with respect to the engagement of communities in the design of the EbA activities..." See also project submission, p. 51, para 140: “The project's activities have been designed to be transparent and will maintain a broadly consultative approach throughout the implementation period. The proposed approach to identifying communities to participate in the project's activities will borrow from the ongoing approach used by Department of Forestry to identify potential Community Forestry Committees. This includes provisions such as minimum standards for establishing mechanisms for conflict resolution, registry of disputes and complaints, and other measures to ensure that the project's activities are transparent and adheres to the principles of FPIC (free, prior, and informed consent)."

62 See, for example, IFC PS7, GN 34, which states: "FPIC entails consent for specific activities, impacts, and mitigation measures as anticipated at the time when consent is given" and GN 40: "FPIC can be provided at a single point in time." PS 7, GN 40 notes only, "Projects with long life cycles may elect to develop an agreement that involves commitments being delivered through periodic development plans covering defined project planning periods."

${ }^{63}$ See Development Bank of South Africa (DBSA) Environmental and Social Safeguard Standards, p. 49. 


\section{${ }^{64}$ Forest Peoples Programme and Tebtebba. 2015. The Green Climate Fund and Free, Prior and Informed Consent and a Call for the Adoption of an Indigenous Peoples' Policy: Lessons from a Wetland Project in Peru.}

FPP and Tebtebba.

65 Project submission, p. 49. The participants signed minutes to indicate their acceptance of, satisfaction with, and commitment to the proposed project. A recording of the consultation meetings is available here.

${ }^{66}$ FPP and Tebtebba, 2015 (see endnote 66).

${ }^{67}$ Annex I: List of conditions and recommendations. GCF/B.11/11), p. 5

68 See Report of the sixteenth meeting of the Board (GCF/B.16/24), 4-6 April 2017.

${ }^{69}$ See IFC PS1, p. 3, FN 12.

${ }^{70}$ See IFC PS5, p. 2. See also p. 2, FN 6.

${ }^{71}$ See PS7, para. 8, which requires identification of "all communities of Indigenous Peoples within the project area of influence who may be affected by the project, as well as the nature and degree of the expected direct or indirect economic, social, cultural (including cultural heritage) and environmental impacts on them." See also, PS 7, p.2, GN 10: If potentially adverse impacts are identified "further analysis should be undertaken to collect baseline data on those communities, covering key environmental and socioeconomic aspects that may be impacted by the project." And p. 5: the "breadth, depth, and type" of this additional assessment appears to depend on two factors: (1) the nature and scale of the project's proposed impacts, and (2) the 'vulnerability' of the Affected Communities.

72 See IFC PS 7.

73 The US State Department, for example, recognizes communities in the project area as 'tribes.' Conservation International notes, in a May 10, 2017 email to RRI, that the decision not to treat these communities as indigenous is consistent with their deep understanding of and long experience in Madagascar, as well as practice of other development and conservation actors there. Project partner Althelia Ecosphere also notes 'The Madagascar Climate and Conservation Fund will also apply the IFC Performance Standards as required under Althelia's ESG policy. Consistent with IFC PS7 and the EIB ESPS we will therefore identify any indigenous or forest peoples who may be affected by any potential investment prior to investment, and will not proceed without verification of FPIC, which is also something we will track in on-going monitoring.'

${ }^{74}$ Huff, Amber R. 2012. Exploring discourses of indigeneity and rurality in Mikea Forest environmental governance. Madagascar Conservation \& Development, 7(2). Citing extensive research, the author notes that "Because Malagasy people living in rural localities may have limited means to counter dominant narratives or participate fully in policy discussions, stakeholders possessing greater social power shape the context in which discussions about environmental governance and rights take place, can specify who is qualified to make decisions about environmental management, and can frame problems so that certain courses of action are justified while a variety of alternative perspectives and courses of action are never considered." Referencing the highly politicized concept of 'indigenous peoples,' she adds that "Identifying who qualifies as indigenous can be problematic, especially when these categories are not meaningful to the people who are objects of policy action. Such problems are exacerbated when procedures for achieving free, prior, and informed consent for conservation and development projects are conceptually and logistically challenging to practitioners on the ground," Among other things, they "contribute to significant gaps among prescribed policy, realized legislation and protocols, and micro-regional conservation and development practice. This risks widening gaps between 
anticipated results (in terms of social outcomes, and for landscape and biodiversity preservation) and realized local outcomes for particular projects."

${ }^{75}$ Environmental and Social Management Framework, p. 14

${ }^{76}$ See UN-REDD Programme Guidelines on Free, Prior and Informed Consent, Annex 1.

77 See ILO Indigenous and Tribal Peoples Convention No. 169.

78 These characteristics include, among others: collective attachment to customary and traditional territories, lands and resources, including groups for whom such attachments have been forcibly severed; priority in time in the lands and territories they occupy; distinct cultural, social, economic institutions, potentially including distinctive languages, customary laws, and other distinct forms of social organization; and experience of subjugation or marginalization in relation to dominant society. This draws on the work of Jose R. Martinez Cobo, the Special Rapporteur of the Sub-Commission on Prevention of Discrimination and Protection of Minorities, in his Study on the Problem of Discrimination against Indigenous Populations.

79 See IFC PS 1, paras. 26 and 27. PS 1 requires the identification of "Affected Communities" when projects are likely to generate adverse environmental and social impacts. Para. 28 stipulates that when project areas are undefined, but "reasonably expected to have significant impacts on local communities," proponents need to be develop a Stakeholder Engagement Framework as part of their management plan. Para. 30 notes that consultation should begin early, with relevant, easily accessible and understandable information, enabling 'meaningful participation,' and be documented. Clients must tailor the process to the decision-making processes of Affected Communities and the needs of disadvantaged or vulnerable groups.

${ }^{80}$ See IFC PS 1, para. 31, ICP must involve in-depth exchange of views and information, through iterative consultation, to incorporate communities' views on mitigation measures, benefits/opportunities, and implementation. This process must be documented, and communities informed about how concerns have been considered.

81 See IFC PS 1, para. 29

82 See IFC PS 1, para. 27: The plan must be "scaled to the project risks and impacts and development stage" and tailored to the characteristics and interests of Affected Communities. When disadvantaged or vulnerable communities are part of the stakeholder group, the plan must include differentiated measures to allow for their effective participation. When community 'representatives' are involved in decision-making, 'every reasonable effort' must be made to verify that these persons represent the views of Affected Communities.

${ }^{83}$ See Annex XIV of the Board meeting GCF/B.08/45.

${ }^{84}$ See GCF Independent Technical Advisory Panel's Assessment (GCF/B.13/16/Add.12/Rev.01).

${ }^{85}$ See GCF Decisions of the Board - Thirteenth meeting of the Board (GCF/B.13/32/Rev.01), p. 79.

${ }^{86}$ See project submission, p. 58.

${ }^{87}$ See Sohn, Jonathon et al. 2007. Development Without Conflict, The Business Case for Consent. Washington, DC; WRI. Available at: http://www.wri.org/publication/development-without-conflict.

${ }^{88}$ These include the Madagascar Smallholders Project, the Pacific RE-Invest Project, the South African MSME Project, the Caribbean SEF Project, the Gambian EbA Project, the CAMP4ASB, the Maldives Water Project, the Tuvalu Adaptation Project and the Argentina Sustainable Energy Project. 
${ }^{89}$ See project submission, p. 14.

90 See updated Terms of Reference of the GCF Independent Redress Mechanism.

${ }^{91}$ See SEF Environmental and Social Management Report (2015).

${ }^{92}$ See proposal's Environmental and Social Management Plan, para. 20.

93 World Bank. 2014. Global Review of Grievance Redress Mechanisms in World Bank Projects. Washington, DC: World Bank.

94 The ESS, secured upon request, notes only that the EIF has a 'community engagement mechanism through which community grievances will be received and managed. See ESS, p. 49.

${ }^{95}$ See project submission, p. 51.

${ }^{96}$ See project submission, p. 54.

97 See project submission, p. 20.

${ }^{98}$ The accredited entity (DBSA) and implementing entity (SCF) detailed overview of the grievance system used, including procedures to receive, document and respond to questions or complaints from the general public. See "customer complaints" in www.dbsa.org and "contact us" in www.scfcap.com.

${ }^{99}$ See project submission, p. 34.

100 See project submission, p. 11, 51, 54: "The general environmental risks associated with the project beneficiaries' day to day business may include among others, compliance with environmental legislation, norms and standards, environmental incidents, etc. These risks need to be mitigated by the project beneficiaries themselves, but the DBSA (AE) monitoring should assist in making sure there is compliance.' ESS requirement and monitoring and evaluation regime of the DBSA will ensure compliance."

101 See project submission, p. 55.

102 See project submission, p. 53.

103 These include the Maldives Water Project, The Gambian EbA Project, the Caribbean SEF Project, and the Argentina Sustainable Energy Project.

104 See project submission, p. 56: “DBSA (AE) monitoring to closely monitor this target and ensure compliance Fund criteria to be aligned with gender targets."

105 See project submission, p. 22.
106 See project submission, p. 28. 